\title{
A rapid advice guideline for the diagnosis and treatment of 2019 novel coronavirus (2019-nCoV) infected pneumonia (standard version)
}

Ying-Hui Jin ${ }^{1}$, Lin Cai ${ }^{2}$, Zhen-Shun Cheng ${ }^{3}$, Hong Cheng ${ }^{4}$, Tong Deng ${ }^{1,5}$, Yi-Pin Fan ${ }^{6,7}$, Cheng Fang ${ }^{1}$, Di Huang ${ }^{1}$, Lu-Qi Huang ${ }^{6,7}$, Qiao Huang ${ }^{1}$, Yong Han ${ }^{2}$, Bo Hu ${ }^{8}$, Fen Hu ${ }^{8}$, Bing-Hui Li ${ }^{1,5}$, Yi-Rong Li ${ }^{9}$, Ke Liang ${ }^{10}$, Li-Kai Lin ${ }^{2}$, Li-Sha Luo ${ }^{1}$, Jing Ma ${ }^{8}$, Lin-Lu Ma', Zhi-Yong Peng ${ }^{8}$, Yun-Bao Pan ${ }^{9}$, Zhen-Yu Pan ${ }^{11}$, Xue-Qun Ren ${ }^{5}$, Hui-Min Sun ${ }^{12}$, Ying Wang ${ }^{13}$, Yun-Yun Wang ${ }^{1}$, Hong Weng ${ }^{1}$, Chao-Jie Wei ${ }^{3}$, Dong-Fang $\mathrm{Wu}^{4}$, Jian Xia ${ }^{14}$, Yong Xiong ${ }^{10}$, Hai-Bo Xu ${ }^{15}$, Xiao-Mei Yao ${ }^{16}$, Yu-Feng Yuan ${ }^{2}$, Tai-Sheng Ye ${ }^{17}$, Xiao-Chun Zhang ${ }^{15}$, Ying-Wen Zhang ${ }^{17}$, Yin-Gao Zhang ${ }^{2}$, Hua-Min Zhang ${ }^{6,7}$, Yan Zhao ${ }^{14}$, Ming-Juan Zhao ${ }^{1}$, Hao Zi ${ }^{1,5}$, Xian-Tao Zeng ${ }^{1,18^{*}}$, Yong-Yan Wang ${ }^{6,7^{*}}$, Xing-Huan Wang ${ }^{1,2^{*}}$, for the Zhongnan Hospital of Wuhan University Novel Coronavirus Management and Research Team, Evidence-Based Medicine Chapter of China International Exchange and Promotive Association for Medical and Health Care (CPAM)

\begin{abstract}
In December 2019, a new type viral pneumonia cases occurred in Wuhan, Hubei Province; and then named "2019 novel coronavirus (2019-nCoV)" by the World Health Organization (WHO) on 12 January 2020. For it is a never been experienced respiratory disease before and with infection ability widely and quickly, it attracted the world's attention but without treatment and control manual. For the request from frontline clinicians and public health professionals of 2019-nCoV infected pneumonia management, an evidence-based guideline urgently needs to be developed. Therefore, we drafted this guideline according to the rapid advice guidelines methodology and general rules of WHO guideline development; we also added the first-hand management data of Zhongnan Hospital of Wuhan University. This guideline includes the guideline methodology, epidemiological characteristics, disease screening and population prevention, diagnosis, treatment and control (including traditional Chinese Medicine), nosocomial infection prevention and control, and disease nursing of the 2019-nCoV. Moreover, we also provide a whole process of a successful treatment case of the severe 2019-nCoV infected pneumonia and experience and lessons of hospital rescue for 2019-nCoV infections. This rapid advice guideline is suitable for the first frontline doctors and nurses, managers of hospitals and healthcare sections, community residents, public health persons, relevant researchers, and all person who are interested in the 2019-nCoV.
\end{abstract}

Keywords: 2019 novel coronavirus, 2019-nCoV, Respiratory disease, Pneumonia, Infectious diseases, Rapid advice guideline, Clinical practice guideline, Evidence-based medicine

\footnotetext{
* Correspondence: zengxiantao1128@163.com; wangyyanpublic@bta.net.cn;

wangxinghuan1965@163.com

Except the first and corresponding authors, the rest of authors were

alphabetized by their last name and contributed equally.

${ }^{1}$ Center for Evidence-Based and Translational Medicine, Zhongnan Hospital

of Wuhan University, Wuhan 430071, China

${ }^{6}$ China Academy of Chinese Medical Sciences, Beijing 100700, China

Full list of author information is available at the end of the article
}

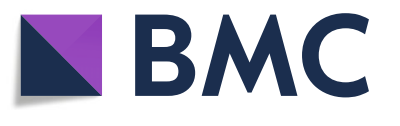

(c) The Author(s). 2020 Open Access This article is distributed under the terms of the Creative Commons Attribution 4.0 International License (http://creativecommons.org/licenses/by/4.0/), which permits unrestricted use, distribution, and

reproduction in any medium, provided you give appropriate credit to the original author(s) and the source, provide a link to the Creative Commons license, and indicate if changes were made. The Creative Commons Public Domain Dedication waiver (http://creativecommons.org/publicdomain/zero/1.0/) applies to the data made available in this article, unless otherwise stated. 


\section{Background}

In December 2019, the 2019 novel coronavirus (2019$\mathrm{nCoV}$ ) was discovered and identified in the viral pneumonia cases that occurred in Wuhan, Hubei Province, China; And then was named by the World Health Organization (WHO) on 12 January 2020. In the following month, the 2019-nCoV quickly spreading inside and outside of Hubei Province and even other countries. What's more, the sharp increase of the case number caused widespread panic among the people.

Medical professionals require an up-to-date guideline to follow when an urgent healthcare problem emerging. In response to the requests for reliable advice from frontline clinicians and public healthcare professionals managing 2019-nCoV pandemics, we developed this rapid advance guideline, involving disease epidemiology, etiology, diagnosis, treatment, nursing, and hospital infection control for clinicians, and also for public health workers and community residents.

\section{Guideline methodology}

This guideline was prepared in accordance with the methodology and general rules of WHO Guideline Development and the WHO Rapid Advice Guidelines [1, 2].

\subsection{Composition of the guideline development group}

This guideline development group is multidisciplinary and composed of individuals from health professionals and methodologists. Health professionals included frontline clinical doctors, nurses who work in departments of respiratory medicine, fever clinic, critical medicine, emergency, infectious disease, and experts of respiratory infectious disease and hospital management board. The methodologists included methodologists of guideline development, systematic review, and literature searching professionals.

\subsection{The end-user of the guideline}

This guideline is suitable for frontline doctors and nurses, managers of hospitals and healthcare sections, healthy community residents, personnel in public healthcare, relevant researchers, and all persons who are interested in the 2019-nCoV management.

\subsection{The target population of the guideline}

This guideline is aimed to serve the healthcare professionals to tackle the suspected 2019-nCoV infected cases, confirmed 2019-nCoV infected cases, clustered 2019-nCoV infected cases, and those with close contacts or suspicious exposure to 2019-nCoV infected cases.

\subsection{A survey of conflict of interests}

Oral inquiry for financial interests of relevant personal was conducted at the first meeting while to start this guideline. Relevant financial as well as nonfinancial interests were surveyed and disclosed and subsequently assessed in consensus conference in order to minimize potential bias in guideline development. Finally, there is no conflict of interests for all the personnel participating to prepare this guideline.

\subsection{Guideline's structural setup and refining the topics and coverage of this guideline}

This guideline is a rapid guideline to responding to the emerging infectious disease of 2019-nCoV. Due to the urgent need and tight work schedule, we conducted no wide-range survey but a discussion meeting with front-line clinicians who managed patients with 2019-nCoV infections to finalize guideline topics and key questions.

\subsection{Literature searching and preparation of evidence profiles}

\subsubsection{General notes}

Considering the lack of direct evidence for this newly identified 2019-nCoV infection, we searched and referred to the guidelines that related to the SARS (Severe Acute Respiratory Syndrome), MERS (Middle East Respiratory Syndrome), and influenza. We also referred to the guidelines which were newly-issued by the National Health Commission of People's Republic of China and WHO for 2019-nCoV. In addition, we have an independent literature searching team to search available indirect evidence from systematic reviews and/or RCTs (randomized controlled trials), which were for the treatment and/ or chemoprophylaxis of SARS, MERS, or other influenza virus infections.

If the existing evidence addressed topics or questions covered by the guideline, then its quality should be assessed. If there is a lack of higher-level quality evidence, our panel considered observational studies and case series. Because of the limited time, we did not perform new systematic review. We identified relevant literature up to 20 January 2020.

\subsubsection{Search resources}

We searched the bibliographic databases: PubMed, Embase, and Cochrane library.

We also searched following websites: the WHO (https://www.who.int/), CDC (Centers for Disease Control and Prevention, https://www.cdc.gov/), NICE (National Institute for Health and Clinical Excellence, https://www.nice.org.uk/), National Health Commission of the People's Republic of China (http://www.nhc.gov. $\mathrm{cn} /$ ), and National Administration of Traditional Chinese Medicine (http://www.satcm.gov.cn/). 


\subsubsection{Frontline data collection and summary}

As the $2019-\mathrm{nCoV}$ is a newly identified pathogen responsible for the outbreak of the pandemic disease, there is no sufficient evidence to reveal the whole nature of this virus. In these situations, obtaining evidence from the experts who fighting the disease on the frontline can be efficient and the main source [3].

Until to 24:00 on 29 January 2020, 11,500 persons were screened, and 276 were identified as suspected infectious victims, and 170 were diagnosed (including 33 in critical condition) for 2019-nCoV infection in Zhongnan Hospital of Wuhan University. During this process, frontline clinicians and nurses have accumulated valuable experience in the diagnosis, treatment and nursing for $2019-\mathrm{nCoV}$ infected patients. Hence, these experiences were assessed and then used as "Expert Evidence" for our guideline development. We took interviews and group surveys to collect information on treatment evidence during the guideline panel's meeting, so that it could be integrated into the guideline panel in the summary of findings (see Additional files 1 and 2). Experts' evidence can be solicited by the description of case reports, summaries, and reports of topics or questions of all cases they management.

\subsection{Grading the evidences and recommendations}

We accorded to the Grading of Recommendations Assessment, Development and Evaluation (GRADE) basic approaches and rules $[4,5]$, and particularly considered experts' evidence to assess the quality of a body of evidence to make recommendations.

The quality of evidence reflects whether the extent to which our confidence estimating the effect is adequate to support a particular recommendation. The level of evidence was categorized as "high quality", "moderate quality", "low quality", or "very low quality"; Recommendations were classified as "strong" or "weak."

The strong recommendation does not always mean there is sufficient intervention effectiveness. Besides the effectiveness of intervention, the forming of recommendations is based on the severity of the disease, patient willingness, safety, and economics [4]. See Tables 1 and $2[4,6]$.

Table 1 Classification and description of recommendation

\begin{tabular}{ll}
\hline $\begin{array}{l}\text { Classification of } \\
\text { recommendation }\end{array}$ & Description \\
\hline Strong recommendation & $\begin{array}{l}\text { It is definite that the desirable effects } \\
\text { of an intervention outweigh its } \\
\text { undesirable effects or the undesirable } \\
\text { effects of an intervention outweigh its } \\
\text { desirable effects }\end{array}$ \\
Weak recommendation & $\begin{array}{l}\text { The desirable effects probably outweigh } \\
\text { the undesirable effects or undesirable } \\
\text { effects probably outweigh the desirable } \\
\text { effects }\end{array}$ \\
\hline
\end{tabular}

\subsection{Forming the recommendations}

Before meetings, experts' evidence was collected systematically and available to panel members. Once the evidence has been identified and assessed, recommendations were formulated based on the evidence by a face-to-face meeting of panel members and supplemented by experts participating in the panel meeting.

Experts' evidence was highly valued in this guideline development. During the consensus process, if the evidence was agreed on by more than $70 \%$ frontline clinicians in the consensus meeting, it is considered as highquality evidence.

In specific recomendations, we used "should" or "strongly recommend" for strong recommendations; whereas, "suggest" or "consider" was used for weak ones.

\subsection{Drafting and publishing the guideline}

This guideline was published in both Chinese and English versions at the same time. Due to space limitations, the current standard revision does not include evidence descriptions. The full revision will be published in New Medicine (Chinese name: Yixue Xinzhi; http://www. jnewmed.com/), Volume 30 and Issue 12020 [7].

\section{Epidemiological characteristics}

\subsection{Scope of the 2019-nCoV infection outbreak}

Since December 2019, multiple cases occurring unexplainable pneumonia were successively reported in some hospitals in Wuhan city with a history of exposure to a large Hua'nan seafood market in Wuhan city, Hubei province, China. It has been confirmed to be an acute respiratory infection caused by a novel coronavirus. So far, the number of cases without a history of the Hua'nan seafood market exposure is increasing. In addition, clustered cases and confirmed cases without a history of travel to Wuhan emerged. Also, confirmed cases without clear exposure to the Wuhan seafood market have been found in many foreign countries or regions [8].

At 24:00 on 26 January 2020, the National Health Commission of the People's Republic of China has recorded a total of 2744 confirmed cases of pneumonia with 2019-nCoV infection from 30 provinces (districts and cities), including 461 severe cases and 80 deaths. A total of 51 cases have been cured and discharged. At present, 5794 suspected cases were recorded, 32,799 with close contacts to the confirmed patients have been tracked, 583 people were released from medical observation that day, and 30,453 people were still undergoing medical observation. A total of confirmed cases were reported from Hong Kong, Macao and Taiwan of China: 8 cases in Hong Kong, 5 cases in Macao, and 4 cases in Taiwan. In addition, confirmed cases had been reported from abroad: 7 in Thailand, 4 in Australia, 4 in Singapore, 3 in France, 3 in Japan, 3 in Korea, 3 in 
Table 2 Rules for grading the recommendations

\begin{tabular}{|c|c|c|c|}
\hline $\begin{array}{l}\text { Strength of recommendation } \\
\text { and quality of evidence }\end{array}$ & Benefit vs. risk and burdens & Methodological quality of supporting evidence ${ }^{a}$ & Implications \\
\hline $\begin{array}{l}\text { Strong recommendation, } \\
\text { high-quality evidence }\end{array}$ & $\begin{array}{l}\text { Benefits clearly outweigh risk } \\
\text { and burdens, or vice versa }\end{array}$ & $\begin{array}{l}\text { RCTs without important } \\
\text { limitations or overwhelming } \\
\text { evidence from observational } \\
\text { studies }\end{array}$ & $\begin{array}{l}\text { Strong recommendation, } \\
\text { can apply to most patients } \\
\text { in most circumstances } \\
\text { without reservation }\end{array}$ \\
\hline $\begin{array}{l}\text { Strong recommendation, } \\
\text { moderate quality evidence }\end{array}$ & $\begin{array}{l}\text { Benefits clearly outweigh risk } \\
\text { and burdens, or vice versa }\end{array}$ & $\begin{array}{l}\text { RCTs with important limitations } \\
\text { (inconsistent results, methodological } \\
\text { flaws, indirect or imprecise) or } \\
\text { exceptionally strong evidence from } \\
\text { observational studies }\end{array}$ & $\begin{array}{l}\text { Strong recommendation, } \\
\text { can apply to most patients } \\
\text { in most circumstances } \\
\text { without reservation }\end{array}$ \\
\hline $\begin{array}{l}\text { Strong recommendation, low } \\
\text { or very low quality evidence }\end{array}$ & $\begin{array}{l}\text { Benefits clearly outweigh risk } \\
\text { and burdens, or vice versa }\end{array}$ & Observational studies or case series & $\begin{array}{l}\text { Strong recommendation } \\
\text { but may change when } \\
\text { higher quality evidence } \\
\text { becomes available }\end{array}$ \\
\hline $\begin{array}{l}\text { Weak recommendation, } \\
\text { high-quality evidence }\end{array}$ & $\begin{array}{l}\text { Benefits closely balanced with } \\
\text { risks and burden }\end{array}$ & $\begin{array}{l}\text { RCTs without important limitations } \\
\text { or overwhelming evidence from } \\
\text { observational studies }\end{array}$ & $\begin{array}{l}\text { Weak recommendation, } \\
\text { best action may differ } \\
\text { depending on circumstances } \\
\text { or patients' or societal values }\end{array}$ \\
\hline $\begin{array}{l}\text { Weak recommendation, } \\
\text { moderate quality evidence }\end{array}$ & $\begin{array}{l}\text { Benefits closely balanced with } \\
\text { risks and burden }\end{array}$ & $\begin{array}{l}\text { RCTs with important limitations } \\
\text { (inconsistent results, methodological } \\
\text { flaws, indirect or imprecise) or } \\
\text { exceptionally strong evidence from } \\
\text { observational studies }\end{array}$ & $\begin{array}{l}\text { Weak recommendation, } \\
\text { best action may differ } \\
\text { depending on circumstances } \\
\text { or patients' or societal values }\end{array}$ \\
\hline $\begin{array}{l}\text { Weak recommendation, low } \\
\text { or very low quality evidence }\end{array}$ & $\begin{array}{l}\text { Uncertainty in the estimates of } \\
\text { benefits, risks and burden; benefits, } \\
\text { risk and burden may be in a closely } \\
\text { balanced }\end{array}$ & Observational studies or case series & $\begin{array}{l}\text { Very weak recommendations; } \\
\text { other alternatives may be } \\
\text { equally reasonable }\end{array}$ \\
\hline
\end{tabular}

RCTs randomized controlled trials

${ }^{a}$ The evidence agreed on by more than $70 \%$ frontline clinicians in consensus meeting is viewed as high-quality evidence

Malaysia, 3 in the United States, 2 in Vietnam, and one in Nepal [9].

\subsection{Host and reservoir}

Wild animal, bats [10] is the most possible host of the 2019-nCoV. It requires further confirmation whether pneumonia infected by the $2019-\mathrm{nCoV}$ is transmitted directly from bats or through an intermediate host. It is believed that clarifying the source of the virus will help determine zoonotic transmission patterns [11].

\subsection{Route of transmission}

Up to present, the main infection source was the patients who with pneumonia infected by the 2019-nCoV. Respiratory droplet transmission is the main route of transmission, and it can also be transmitted through contact [12]. Although many details, such as the source of the virus and its ability to spread between people remain unknown, an increasing number of cases show the signs of human-tohuman transmission $[8,13]$.

\subsection{Etiology and pathogenesis}

The 2019-nCoV isolated from the lower respiratory tract of patients with unexplainable pneumonia in Wuhan, and it is a novel coronavirus belonging to the $\beta$ genus. The 2019-nCoV has an envelope; its particles are round or oval, often polymorphic, with a diameter from $60 \mathrm{~nm}$ to $140 \mathrm{~nm}$. Its genetic characteristics are significantly different from SARSr-CoV (SARS related coronaviruses) and MERSr-CoV (MERS related coronaviruses). Current research shows it has more than $85 \%$ homology with SARSr-CoV (bat-SL-CoVZC45). 2019-nCoV can be found in human respiratory epithelial cells $96 \mathrm{~h}$ after in vitro isolation and culture, while it takes about 6 days in VeroE6 or Huh-7 cell lines [12].

The source of the virus, the time span of the patients discharging infective virus, and the pathogenesis are still not clear [14].

\subsection{Molecular epidemiology}

No evidence of viral mutation has been found so far [14]. It is necessary to obtain much more clinically isolated viruses with time and geographical variety to assess the extent of the virus mutations, and also whether these mutations indicate adaptability to human hosts [11].

\subsection{Incubation and contagious period}

Based on currently epidemiological survey, the latency period is generally from 3 to 7 days, with a maximum of 14 days [10]. Unlike SARSr-CoV, 2019-nCoV is contagious during the latency period [15]. 


\subsection{Prognostic factors}

The population is generally susceptible to the virus. The elderly and those with underlying diseases show more serious conditions after infection, and children and infants also get infected by the 2019-nCoV. From current knowledge of the cases, most patients have a good prognosis, the symptoms of children are relatively mild, and a few patients are in critical condition. Death cases are more frequently seen in the elderly and those with chronic underlying diseases [12].

The newest study including the first 41 confirmed cases admitted to Wuhan between 16 December 2019 and 2 January 2020 showed the median age of patients was 49 years; and the main underlying diseases were diabetes, hypertension, and cardiovascular diseases. Of them, 12 cases experienced acute respiratory distress syndrome (ARDS), 13 cases were admitted to the intensive care unit (ICU), and 6 cases died [16].

\section{Screening for diseased cases and preventive measures for population}

\subsection{Case definitions}

\subsubsection{Suspected case}

Patients with any 2 of the following clinical features and any epidemiological risk: (1) clinical features: fever, imaging features of pneumonia, normal or reduced white blood cell count, or reduced lymphocyte count in the early stages of the disease onset. (2) epidemiologic risk: a history of travel to or residence in Wuhan city, China or other cities with continuous transmission of local cases in the last 14 days before symptom onset; contact with patients with fever or respiratory symptoms from Wuhan city, China or other cities with continuous transmission of local cases in the last 14 days before symptom onset; or epidemiologically connected to 2019-nCoV infections or clustered onsets [12].

\subsubsection{Confirmed case}

Those with one of the following pathogenic evidence is the confirmed case: (1) positive for the 2019-nCoV by the real-time PCR test for nucleic acid in respiratory or blood samples [17]. 2) viral gene sequencing shows highly homogeneity to the known 2019-nCoV in respiratory or blood samples [12].

\subsubsection{Clustered cases}

Suspected clustering cases are defined when one confirmed case and at the same time, one or more cases of fever or respiratory infection are found in a small area (such as a family, a construction site, a unit, etc.) within 14 days.

Under the above circumstances, 2 or more confirmed cases are found, and there is the possibility of human-tohuman transmission due to close contact or infection due to co-exposure, then it is determined as a clustered case $[8,18]$.

\subsubsection{Close contacts}

Those who have one of the following contacts after the onset of confirmed cases in the absence of effective protection [18]: (1) those who live, study, work, or have close contact with the confirmed cases, or other close contacts such as working closely with or sharing the same classroom or living in the same house with the confirmed case. (2) medical and nursing staffs and their family members living with them, who treated, nursed or visited the confirmed case, or other personnel who have similar close contact with the case, such as providing direct treatment or care of the case, visiting the case or staying in a closed environment where the cases are located; other patients or caregivers in the same room with the case. (3) people who have close contact with the patients in a same transport vehicle, including those who had taken care of the patients on the vehicle; the person who had companied the patients (family members, colleagues, friends, etc.); other passengers and traffic staff considered having likely close contact with the patients by investigation and evaluation. (4) other circumstances considered to be closely contacted with the person with close contact with the patients by the professional investigation and evaluation.

\subsubsection{Suspicious exposure}

Persons with suspicious exposure are those who are exposed without effective protection to processing, sales, handling, distributing, or administrative management of wild animals, materials, and the environments that are positive for the 2019-nCoV test [18].

\subsection{Prevention}

\subsubsection{Persons with close contacts and suspicious exposure}

Persons with close contacts and suspicious exposure should be advised to have a 14-day health observation period, which starts from the last day of contact with the 2019-nCoV infected patients or suspicious environmental exposure. Once they display any symptoms, especially fever, respiratory symptoms such as coughing, shortness of breath, or diarrhea, they should reach out for medical attention immediately [19]. Contact surveillance should be carried out for those who had exposed to accidental contact, low-level exposure to suspected or confirmed patients, i.e. checking any potential symptoms when carrying out daily activities [20]. See Table 3 for details [21].

\subsubsection{Patients with suspected 2019-nCoV infection}

Patients with a suspected infection should be isolated, monitored, and diagnosed in hospital as soon as possible. Doctors should make recommendations based on the patient's situation. Patients with mild symptoms and suspected infection may consider in-home isolation and home care (weak recommendation). Suspected infected with severe symptoms and those who need to stay in 
Table 3 Recommendations for those with close contacts and suspicious exposures

\begin{tabular}{|c|c|c|}
\hline No. & Recommendation items & $\begin{array}{l}\text { Recommendation } \\
\text { strength }\end{array}$ \\
\hline 1 & $\begin{array}{l}\text { Strictly take the observation period } \\
\text { of } 14 \text { days, and go to the hospital } \\
\text { for diagnosis and treatment if } \\
\text { symptoms appear (fever, cough, etc.). }\end{array}$ & Strong \\
\hline 2 & $\begin{array}{l}\text { If available, inform the designated } \\
\text { hospital in advance to send cars to } \\
\text { pick up the patients with symptoms } \\
\text { to the hospital. }\end{array}$ & Weak \\
\hline 3 & $\begin{array}{l}\text { Patients should wear N95 masks } \\
\text { (priority strategy). }\end{array}$ & Strong \\
\hline 4 & $\begin{array}{l}\text { Using disposable surgical mask } \\
\text { (alternative strategy). }\end{array}$ & Weak \\
\hline 5 & $\begin{array}{l}\text { Avoid taking public transportation } \\
\text { to the hospital, choose an ambulance } \\
\text { or private vehicle, and open vehicle } \\
\text { windows for ventilation on the way to } \\
\text { the hospital (priority strategy). }\end{array}$ & Strong \\
\hline 6 & $\begin{array}{l}\text { When walking on the road or waiting } \\
\text { in the hospital, try to stay away from } \\
\text { other people (at least } 1 \mathrm{~m} \text { away) and } \\
\text { wear a mask. }\end{array}$ & Strong \\
\hline 7 & $\begin{array}{l}\text { The family members accompanying } \\
\text { those for inspection should immediately } \\
\text { follow the monitoring recommendations } \\
\text { to close contacts, keep the respiratory } \\
\text { hygiene and clean their hands properly. }\end{array}$ & Strong \\
\hline 8 & $\begin{array}{l}\text { The community or street hospital should } \\
\text { be informed before the suspected contacts } \\
\text { to the hospital. The vehicle used should be } \\
\text { cleaned and disinfected with } 500 \mathrm{mg} / \mathrm{L} \\
\text { chlorine-containing disinfectant, and the } \\
\text { window should be opened for ventilation. }\end{array}$ & Strong \\
\hline
\end{tabular}

hospital for observation by doctor's judgment should follow the isolation guidelines for suspected patients (see Tables 4 and 5 for details).

It should also be noted that: (1) whether the suspected patients should be given in-home isolation and care or not requires careful clinical evaluation and safety assessment by professionals. (2) if the suspected patients do not get improvement in the symptoms or even worsened in condition during home care, they need to go to the doctor for treatment. (3) during the period of home care,

Table 4 Criteria to define patients with suspected mild symptoms

\begin{tabular}{ll}
\hline No. & Definition of suspected patients with mild symptoms \\
\hline 1 & $\begin{array}{l}\text { In-home isolation and care after assessment } \\
\text { by doctor (golden standard) } \\
2\end{array}$ \\
3 & With a fever $<38{ }^{\circ} \mathrm{C}$ \\
4 & The fever can go down by itself \\
5 & No dyspnea, no asthma \\
6 & With or without cough \\
& No underlying chronic diseases, e.g.: heart, lung \\
\hline
\end{tabular}

the patients' medication and symptoms should be closely recorded and their caregivers should also monitor their body temperature daily.

Throughout the period of home care, healthcare personnel should perform regular (e.g., daily) follow-up through face-to-face visits or phone interviews (ideally, if feasible) to follow the progress of symptoms and, if necessary, specific diagnostic tests should be conducted $[14,19,21]$.

\subsubsection{Prevention for travellers (Strong recommendation)}

International visitors should take routine precautions when entering and leaving the affected areas, including avoiding close contacts with people with acute respiratory infection, washing hands frequently, especially after contacting with the sick or their surrounding environment; following appropriate coughing etiquette; and avoiding close contact with live or dead farming animals or bats or other wild animals [22, 23]. Passengers should avoid unnecessary travel as possible.

If they had travelled to Hubei Province (especially Wuhan city) in the past 14 days and is in fever, cough or difficulty in breathing, they should: (1) see a doctor immediately; (2) call the doctor about his/her recent trips and symptoms before going to the doctor's office or emergency room; (3) avoid contact with others; (4) not to travel around; (5) cover mouth and nose with a tissue or sleeve (not hands) when coughing or sneezing; and (6) wash hands with soap and water for at least $20 \mathrm{~s}$. If soap and water are not available, use alcohol-based hand sanitizers [24].

\section{Diagnosis of the 2019-nCoV cases}

\subsection{Clinical manifestation}

The 2019-nCoV infected cases have symptoms like fever, fatigue, dry cough, dyspnea etc., with or without nasal congestion, runny nose or other upper respiratory symptoms $[13,16]$. Despite the atypical symptoms were reported [25], Nan-Shan Zhong, the academician of Chinese Academy of Engineering in an exclusive interview with Xinhua News Agency on 28 January 2020, pointed out that fever is still the typical symptom of $2019-\mathrm{nCoV}$ infection.

\subsection{Physical examination}

Patients with mild symptoms may not present positive signs. Patients in severe condition may have shortness of breath, moist rales in lungs, weakened breath sounds, dullness in percussion, and increased or decreased tactile speech tremor, etc.

\subsection{Imaging examination}

\subsubsection{CT imaging (strong recommendation)}

The imaging findings vary with the patient's age, immunity status, disease stage at the time of scanning, underlying diseases, and drug interventions. 
Table 5 Home care and isolation guidelines for suspected patients with mild symptoms

\begin{tabular}{|c|c|c|}
\hline No. & Recommendation items & $\begin{array}{l}\text { Recommendation } \\
\text { strength }\end{array}$ \\
\hline \multicolumn{3}{|c|}{ Suspected patients with mild symptoms } \\
\hline 1 & $\begin{array}{l}\text { Well-ventilated single rooms } \\
\text { (preferred strategy). }\end{array}$ & Strong \\
\hline 2 & $\begin{array}{l}\text { Maintain a bed distance of at } \\
\text { least } 1 \mathrm{~m} \text { from the patient } \\
\text { (alternative strategy). }\end{array}$ & Weak \\
\hline 3 & $\begin{array}{l}\text { Clean and disinfect household } \\
\text { articles using } 500 \mathrm{mg} / \mathrm{L} \text { chlorine- } \\
\text { containing disinfectant frequently } \\
\text { every day (wide range). }\end{array}$ & Strong \\
\hline 4 & Limit visits by relatives and friends. & Strong \\
\hline 5 & $\begin{array}{l}\text { The caregiver should be a healthy } \\
\text { family member without underlying } \\
\text { diseases. }\end{array}$ & Weak \\
\hline 6 & Restrict the patient's activity & Strong \\
\hline 7 & $\begin{array}{l}\text { Open windows for ventilation in } \\
\text { shared areas such as toilets and } \\
\text { kitchens. }\end{array}$ & Strong \\
\hline 8 & $\begin{array}{l}\text { Avoid sharing toothbrush, towel, } \\
\text { tableware, bed sheet and other } \\
\text { items with patients. The patient's } \\
\text { daily necessities are for single use } \\
\text { only and should be placed separately } \\
\text { from that of their family members. }\end{array}$ & Strong \\
\hline 9 & $\begin{array}{l}\text { When coughing or sneezing, it is } \\
\text { necessary to wear a medical mask, } \\
\text { or cover with a paper towel and } \\
\text { bent elbow, and clean hands } \\
\text { immediately after coughing and } \\
\text { sneezing. }\end{array}$ & Strong \\
\hline 10 & $\begin{array}{l}\text { N95 masks should be worn in } \\
\text { the same room with patients } \\
\text { (preferred strategy). }\end{array}$ & Strong \\
\hline 11 & $\begin{array}{l}\text { Disposable surgical mask } \\
\text { (alternative strategy). } \\
\text { Use the mask in strict accordance } \\
\text { with the instruction manual. }\end{array}$ & Weak \\
\hline 12 & $\begin{array}{l}\text { After washing hands with running } \\
\text { water, dry them with a paper towel } \\
\text { (preferred strategy). }\end{array}$ & Strong \\
\hline 13 & $\begin{array}{l}\text { Dry with a towel, and wash } \\
\text { and disinfect the towel daily } \\
\text { (alternative strategy). }\end{array}$ & Weak \\
\hline \multicolumn{3}{|c|}{ Home caregivers } \\
\hline 1 & $\begin{array}{l}\text { Clean and disinfect hands after } \\
\text { contact with the patient, before } \\
\text { leaving patient's room or the } \\
\text { house, before and after eating, } \\
\text { after using the toilet and after } \\
\text { entering house from outside } \\
\text { (for visible contaminant on } \\
\text { hands, wash hands with running } \\
\text { water then use hand disinfection). }\end{array}$ & Strong \\
\hline 2 & $\begin{array}{l}\text { Avoid direct contact with patient's } \\
\text { secretions or discharges, especially } \\
\text { oral or respiratory discharges; avoid } \\
\text { direct contact with patient's feces. }\end{array}$ & Strong \\
\hline
\end{tabular}

Table 5 Home care and isolation guidelines for suspected patients with mild symptoms (Continued)

\begin{tabular}{|c|c|c|}
\hline No. & Recommendation items & $\begin{array}{l}\text { Recommendation } \\
\text { strength }\end{array}$ \\
\hline 3 & $\begin{array}{l}\text { Wear disposable gloves (double layers) } \\
\text { when providing oral and respiratory care } \\
\text { to patients, handling patient's feces and } \\
\text { urine, and cleaning the patient's room, } \\
\text { etc. Wash hands before wearing gloves } \\
\text { and after removing the gloves. }\end{array}$ & Strong \\
\hline 4 & $\begin{array}{l}\text { Wash the patient's clothes, bed } \\
\text { sheets, bath towels, towels, etc. } \\
\text { with ordinary washing soap } \\
\text { and water, or use a washing } \\
\text { machine at } 60-90^{\circ} \mathrm{C} \text { with ordinary } \\
\text { household washing liquid (Strong } \\
\text { recommendation), or routinely wash } \\
\text { them with washing machine after } \\
\text { soaking in low concentration } \\
\text { disinfectant (Weak recommendation). }\end{array}$ & Strong/Weak \\
\hline 5 & $\begin{array}{l}\text { Put the contaminated bedding into } \\
\text { the laundry bag. Do not shake } \\
\text { contaminated clothing and avoid } \\
\text { direct contact. }\end{array}$ & Strong \\
\hline 6 & $\begin{array}{l}\text { The waste generated by the patient } \\
\text { should be put into the closed garbage } \\
\text { bags and replaced frequently. }\end{array}$ & Strong \\
\hline
\end{tabular}

The imaging features of lesions show: (1) dominant distribution (mainly subpleural, along the bronchial vascular bundles); (2) quantity (often more than three or more lesions, occasional single or double lesions); (3) shape (patchy, large block, nodular, lumpy, honeycomblike or grid-like, cord-like, etc.); (4) density (mostly uneven, a paving stones-like change mixed with ground glass density and interlobular septal thickening, consolidation and thickened bronchial wall, etc.); and (5) concomitant signs vary (air-bronchogram, rare pleural effusion and mediastinal lymph nodes enlargement, etc.).

\subsubsection{Clinical data from Zhongnan Hospital of Wuhan University \\ Typical CT/X-ray imaging manifestation, including}

(1) Multiple, patchy, sub-segmental or segmental groundglass density shadows in both lungs. They were classified as "paving stone-like" changes by fine-grid or small honeycomb-like thickening of interlobular septa. The thinner the CT scan layers, the clearer the ground-glass opacity and thickening of interlobular septa were displayed. A slightly high-density and ground-glass change with fuzzy edge in the fine-grid or small honeycomb-like thickening of interlobular septa were presented by the high-resolution computed tomography (HRCT), (Fig. 1: 45 cases, $54.2 \%$ in a total of 83 cases). The resolution of X-ray was worse lower than that of $\mathrm{CT}$ in the resolution, which was basically manifested as ground-glass 

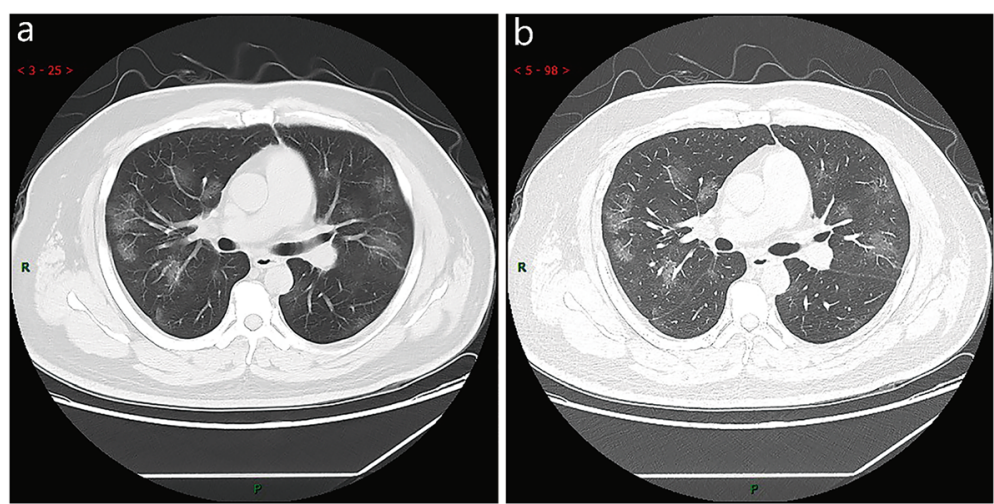

Fig. 1 Typical CT imaging manifestation (case 1). A 38 years old male with fever without obvious inducement $\left(39.3{ }^{\circ} \mathrm{C}\right.$ ), dry cough and shortness of breath for 3 days. Laboratory test: normal white blood cells $\left(6.35 \times 10^{9} / \mathrm{L}\right)$, decreased lymphocytes percentage $(4.1 \%)$, decreased lymphocytes count $\left(0.31 \times 10^{9} / \mathrm{L}\right)$, decreased eosinophil count $\left.\left(0 \times 10^{9} / \mathrm{L}\right)\right)$, increased C-reaction protein $(170.91 \mathrm{mg} / \mathrm{L})$, increased procalcitonin $(0.45 \mathrm{ng} / \mathrm{ml})$. Imaging examination: multiple patches, grid-like lobule and thickening of interlobular septa, typical "paving stone-like" signs. a SL(Slice): 6 mm; b high-resolution computed tomography(HRCT). HRCT. high-resolution computed tomography

opacities with fuzzy edge (Fig. 2: 9 cases, $10.8 \%$ in a total of 83 cases).

(2) Multiple, patchy or large patches of consolidation in both lungs, with a little grid-like or honeycombshaped interlobular septal thickening, especially in the middle and lower lobes (Fig. 3: 26 cases, 31.3\% in a total of 83 cases). It was more common in the elderly or severe condition patients.

\section{Atypical CT/X-ray imaging manifestation, including}

(1) Single, or multiple, or extensive subpleural grid-like or honeycomb-like thickening of interlobular septum, thickening of the bronchial wall, and tortuous and thick strand-like opacity. Several patchy consolidations, occasionally with a small amount pleural effusion or enlargement of mediastinal lymph nodes, can be seen (Fig. 4: 6 cases, 7.2\% in a total of 83 cases). This is mostly seen in the elderly.

(2) Single or multiple solid nodules or consolidated nodules in the center of lobule, surrounded by ground-glass opacities (Fig. 5: 5 cases, 6.2\% in a total of 83 cases).

Stage based on CT image The CT imaging demonstrates 5 stages according to the time of onset and the response of body to the virus, including:

(1) Ultra-early stage. This stage usually refers to the stage of patients without clinical manifestation, negative laboratory test but positive throat swab for 2019-nCoV

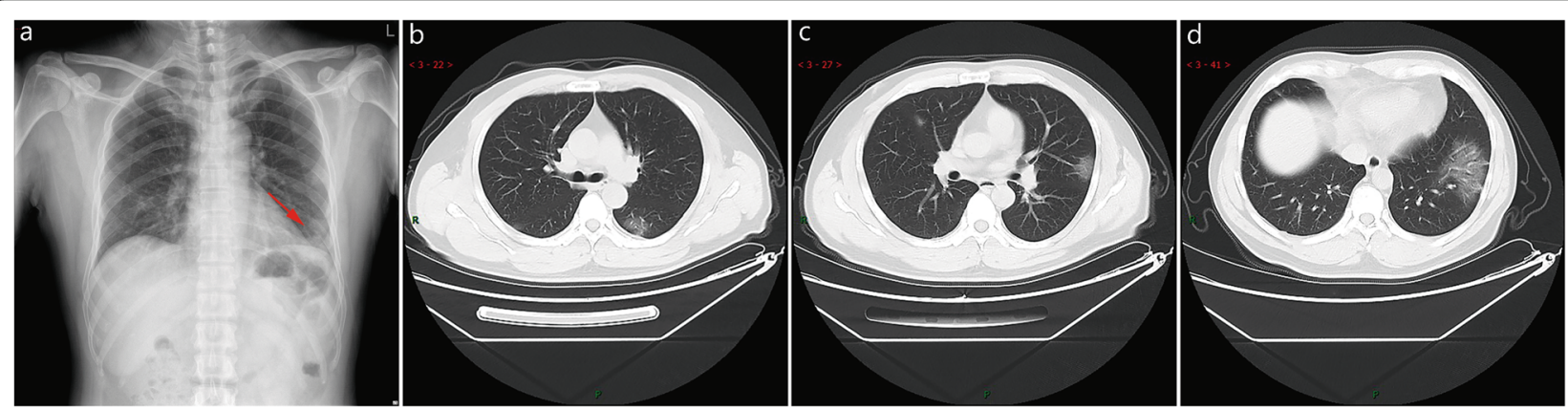

Fig. 2 Typical CT / X-ray imaging manifestation (case 2). A 51 years old male with general muscle ache and fatigue for 1 week, fever for 1 day $\left(39.1{ }^{\circ} \mathrm{C}\right)$, anemia. Laboratory test: normal white blood cells $\left(9.24 \times 10^{9} / \mathrm{L}\right)$, lymphocytes percentage $(5.1 \%)$, decreased lymphocytes $\left(0.47 \times 10^{9} / \mathrm{L}\right)$, decreased eosinophil count $\left(0 \times 10^{9} / \mathrm{L}\right)$, increased C-reaction protein $(170.91 \mathrm{mg} / \mathrm{L})$, increased procalcitonin $(0.45 \mathrm{ng} / \mathrm{ml})$, increased erythrocyte sedimentation rate $(48 \mathrm{~mm} / \mathrm{h})$. Imaging examination: a shows patchy shadows in the outer region of the left lower lobe, $\mathbf{b}$ shows large groundglass opacity in the left lower lobe, and $\mathbf{c}$ shows subpleural patchy ground-glass opacity in posterior part of right upper lobe and lower tongue of left upper lobe, $\mathbf{d}$ shows large ground-glass opacity in the basal segment of the left lower lobe 

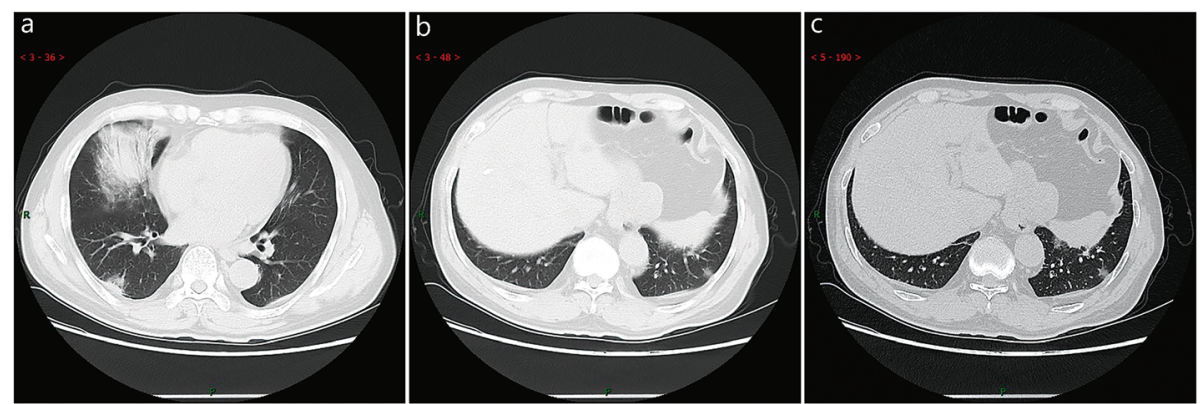

Fig. 3 Typical CT / X-ray imaging manifestation (case 3). A 65 years old male with fever for 4 days $\left(38.7^{\circ} \mathrm{C}\right)$. Laboratory test: normal white blood cells $\left(3.72 \times 10^{9} / \mathrm{L}\right)$, decreased lymphocytes $\left(0.9 \times 10^{9} / \mathrm{L}\right)$, decreased eosinophil count $\left(0 \times 10^{9} / \mathrm{L}\right)$, increased C-reaction protein $(53.0 \mathrm{mg} / \mathrm{L})$, increased procalcitonin $(0.10 \mathrm{ng} / \mathrm{ml})$, reduced liver function, hypoproteinemia, and mild anemia. Imaging examination: $\mathbf{a}$ and $\mathbf{b}$ showed large consolidation in the right middle lobe, patchy consolidation in the posterior and basal segment of the right lower lobe, with air-bronchogram inside, c showed patchy consolidation in the outer and basal segment of the left lower lobe, and a small amount of effusion in the right chest

within 1-2 weeks after being exposed to a viruscontaminated environment (history of contact with a patient or patient-related family members, unit, or medical staff in a cluster environment). The main imaging manifestations are single, double or scattered focal ground-glass opacity, nodules located in central lobule surrounded by patchy ground-glass opacities, patchy consolidation and sign of intra-bronchial air-bronchogram, which was dominant in the middle and lower pleura (Fig. 6: 7 cases, $8.4 \%$ in a total of 83 cases).

(2) Early stage.This stage refers to the period of 1-3 days after clinical manifestations (fever, cough, dry cough, etc.). The pathological process during this stage is dilatation and congestion of alveolar septal capillary, exudation of fluid in alveolar cavity and interlobular interstitial edema. It showed that single or multiple scattered patchy or agglomerated ground-glass opacities, separated by honeycomb-like or grid-like thickened of interlobular septa (Fig. 7: 45 cases, 54.2\% in a total of 83 cases).
(3) Rapid progression stage. This stage refers to the period about 3-7 days after clinical manifestations started, the pathological features in this stage are the accumulation of a large number of cell-rich exudates in the alveolar cavity, vascular expansion and exudation in the interstitium, both of which lead to further aggravation of alveolar and Interstitial edema. The fibrous exudation connects each alveolus through the inter-alveolar space to form a fusion state. The CT manifested a fused and large-scale light consolidation with air-bronchogram inside (Fig. 8: 17 cases, $20.5 \%$ in a total of 83 cases).

(4) Consolidation stage. This stage refers to the period around 7-14days after clinical manifestations appeared. The main pathological features in this stage are the fibrous exudation of the alveolar cavity and the disappearance of capillary congestion in the alveolar wall. CT imaging showed the multiple patchy consolidations in slighter density and smaller range than that of the previous stage. (Fig. 9: 26 cases, $31.2 \%$ in a total of 83 cases).

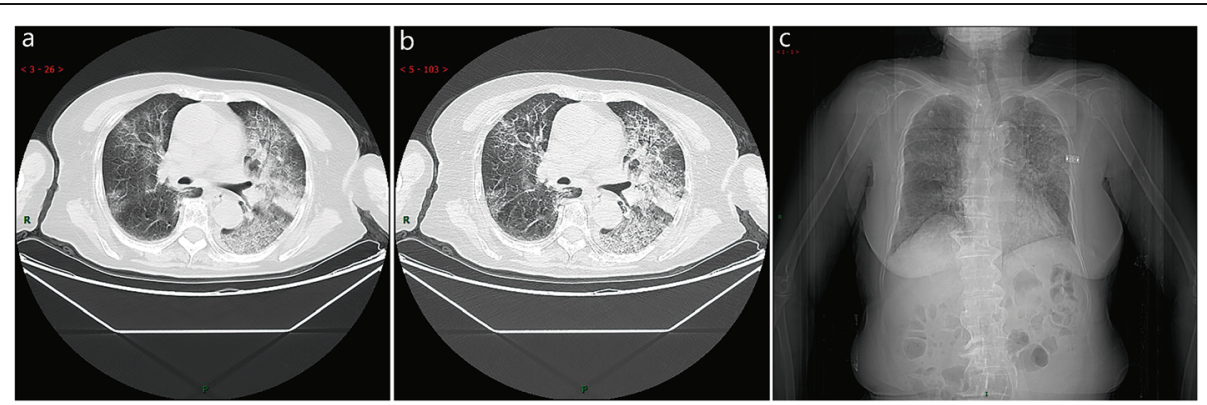

Fig. 4 Atypical CT / X-ray imaging manifestation (case 1). An 83 years old female with fever for 4 days (maximum temperature of $38.8{ }^{\circ} \mathrm{C}$ ), cough, chills, sore throat, dry cough for 1 week, chest tightness and shortness of breath aggravating for 1 week. Laboratory test: normal white blood cells $\left(4.6 \times 10^{9} / \mathrm{L}\right)$, normal neutrophil percentage (65.8\%), decreased lymphocytes percentage (19.9\%). Imaging examination: a and $\mathbf{b}$ showed diffuse interlobular septum thickening in both lungs to form a grid opacity, thickening of bronchial wall, and consolidation in the left sublobal lung. $\mathbf{c}$ showed diffused grid-like opacities in both lungs, especially in the left lung 


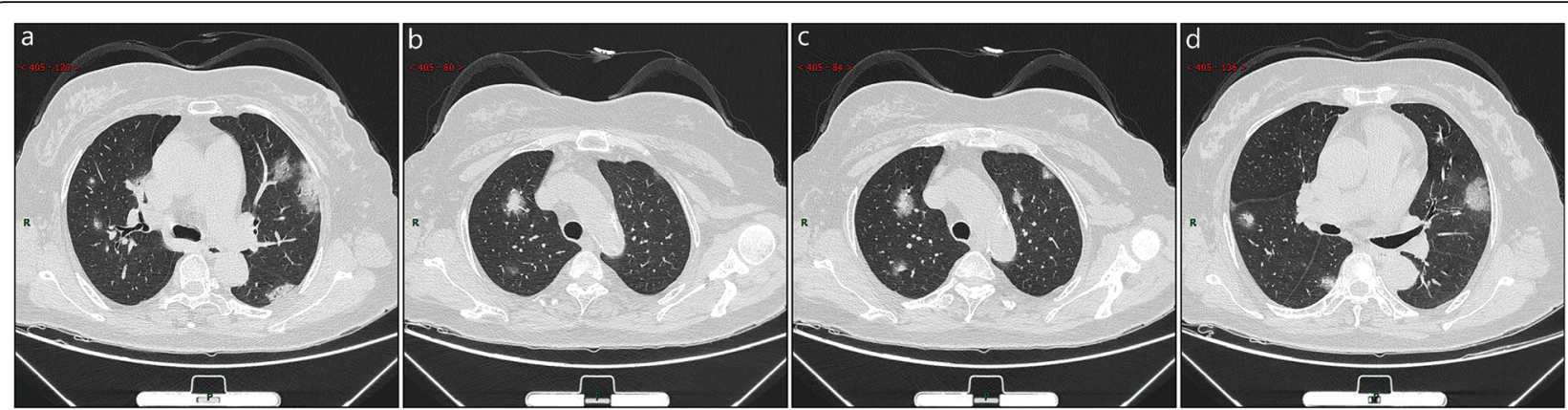

Fig. 5 Atypical CT / X-ray imaging manifestation (case 2). A 56 years old female with fever for 3 days. Laboratory test: decreased total protein $(54.0 \mathrm{~g} / \mathrm{L})$,decreased albumin $(35.5 \mathrm{~g} / \mathrm{L})$,decreased globulin $(18.5 \mathrm{~g} / \mathrm{L})$, normal white blood cells $\left(4.87 \times 10^{9} / \mathrm{L}\right)$, decreased lymphocytes percentage $(10.1 \%)$, decreased lymphocytes $\left(0.49 \times 10^{9} / \mathrm{L}\right)$, decreased eosinophil count $\left.\left(0 \times 10^{9} / \mathrm{L}\right)\right)$, decreased eosinophil count percentage $(0 \%)$. Imaging examination: a showed two consolidation nodulesat the center of the lateral segment of middle lobe of the right lung which was surrounded by ground-glass opacities; $\mathbf{b}$ showed patchy ground-glass opacity in the anterior segment of the right upper lung with patchy consolidation lesions in it; c showed patchy ground-glass opacities in both lungs with patchy consolidation lesions in it. $\mathbf{d}$ showed patchy consolidation in the groundglass opacities in the middle lobe and dorsal segment of lower lobe of right lung

(5) Dissipation stage. This stage refers to the period roughly between 2 and 3 weeks after the onset of clinical manifestations. The range of lesions was further reduced. CT imaging showed patchy consolidation or strip-like opacity. As time goes on, it showed grid-like thickening of interlobular septum, thickening and strip-like twist of bronchial wall and a few scattered patchy consolidations (Fig. 10: 17 cases, $20.5 \%$ in a total of 83 cases).

\subsection{Differential diagnosis}

It mainly should be distinguished from other known viral virus of pneumonia, such as influenza viruses, parainfluenza virus, adenovirus, respiratory syncytial virus, rhinovirus, human metapneumovirus, SARSr$\mathrm{CoV}$, etc.; and also from mycoplasma pneumonia, chlamydia pneumonia, and bacterial pneumonia. In addition, it should be distinguished from non-infectious diseases, such as vasculitis, dermatomyositis, and organizing pneumonia.

\subsection{Techniques for laboratory tests 5.5.1 Hematology examination}

In the early stage of the disease, the total number of leukocytes decreased or keeps normal, with decreased lymphocyte count or increased or normal monocytes. High attention should be paid on the situation where the absolute value of lymphocyte is less than $0.8 \times 10^{9} / \mathrm{L}$, or the numbers of CD4 and CD8 T cells are significantly decreased, which generally recommend rechecking the blood routine changes after 3 days.

\subsubsection{Detection of pathogens in respiratory tract}

(1) Flu antigens. At present, routinely detected flu antigens are A, B, and H7N-subtypes. Sampling of throat swabs is conducive to early rapid screening for flu because of the fast test, but it has a relatively high false negative rate.

(2) Respiratory virus nucleic acid. The detection of respiratory virus nucleic acid is commonly used to

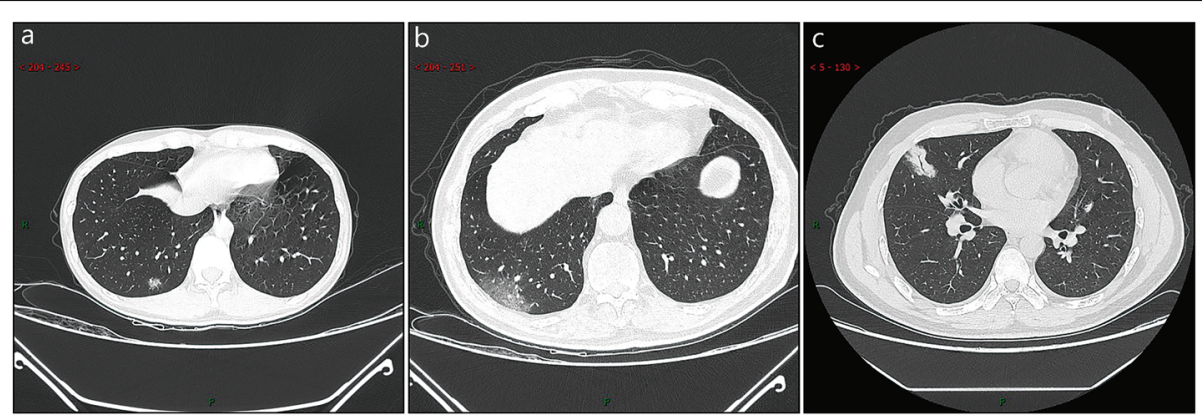

Fig. 6 CT imaging of ultra-early stage. a A 33 years old female with patchy ground-glass opacities after occupational exposure. b A 67 years old male with a history of contact with infected patients, showing large ground-glass opacity. c A 35 years old female exhibiting large consolidated opacity with air-bronchogram inside after occupational exposure 

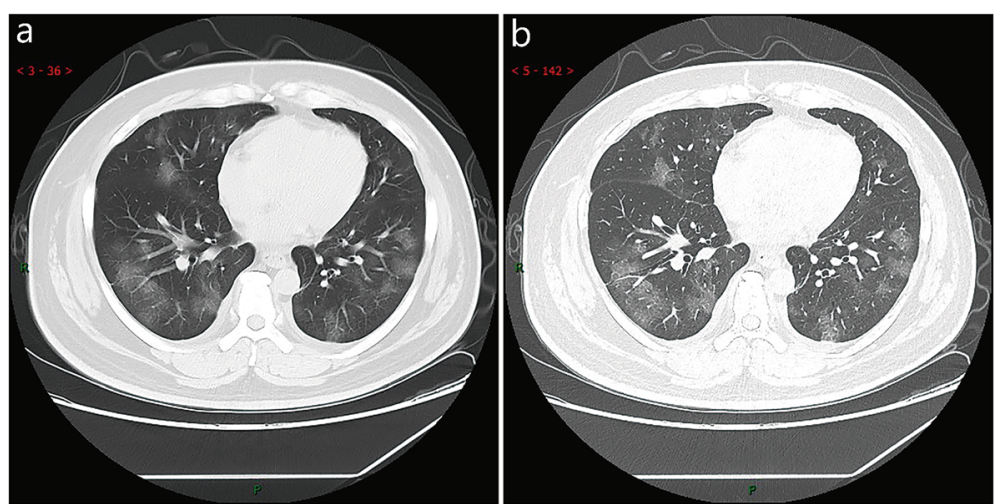

Fig. 7 CT imaging of early stage. Male, 38 years old, fever without obvious inducement $\left(39.3^{\circ} \mathrm{C}\right)$, dry cough and shortness of breath for 3 days. Laboratory test: decreased white blood cells $\left(3.01 \times 10^{9} / \mathrm{L}\right)$, decreased lymphocytes $\left(0.81 \times 10^{9} / \mathrm{L}\right)$, increased C-reaction protein $(60.8 \mathrm{mg} / \mathrm{L})$, increased procalcitonin $(0.16 \mathrm{ng} / \mathrm{ml})$ ). Imaging examination: a (thin layer $\mathrm{CT}$ ) and $\mathbf{b}$ (high-resolution $\mathrm{CT}$ ) showed multiple patchy and light consolidation in both lungs and grid-like thickness of interlobular septa

detect the infection by other common respiratory viruses, mycoplasma and chlamydia infection, such as adenovirus, parainfluenza virus, respiratory syncytial virus, mycoplasma, chlamydia, influenza A and influenza B virus, etc.

(3) 2019-nCoV nucleic acid detection. Accurate RNA detection of $2019-\mathrm{nCoV}$ is with diagnostic value (Strong recommendation). The RNA of 2019-nCoV positive in the throat swab sampling or other respiratory tract sampling by fluorescence quantitative PCR method, especially that from multiple samples and detection kits, excluding sample quality, sample collection time, contaminatory and technical problems, is of great support for etiological diagnosis.

(4) Other laboratory testing. There are other laboratory tests for the status of 2019-nCoV infection, including blood gas analysis, liver and kidney function, myocardial enzyme, myoglobin, erythrocyte sedimentation rate (ESR), C-reactive protein (CRP), Procalcitonin (PCT), lactate, D-dimer, coagulation image, urine routine test, inflammatory factors (interleukin(IL)-6, IL-10, TNF - $\alpha$ ), 11 items of tuberculosis (TB) subgroup, complement, anti-acid staining, etc. Blood gas analysis is helpful to judge the oxygenation of moderately-illed and severe patients. Combining the increase of lactic acid, it is feasible to screen the patients with high-risk of oxygenation disorder. Some infected patients have increased liver enzymes, muscle enzyme, ESR and myoglobin. The detection of CRP and PCT is of certain value to distinguish whether there was bacterial infection in the lung. D-dimer of most severe patients was significantly increased in this epidemic, with frequent clotting disorders and microthrombotic formation in peripheral blood

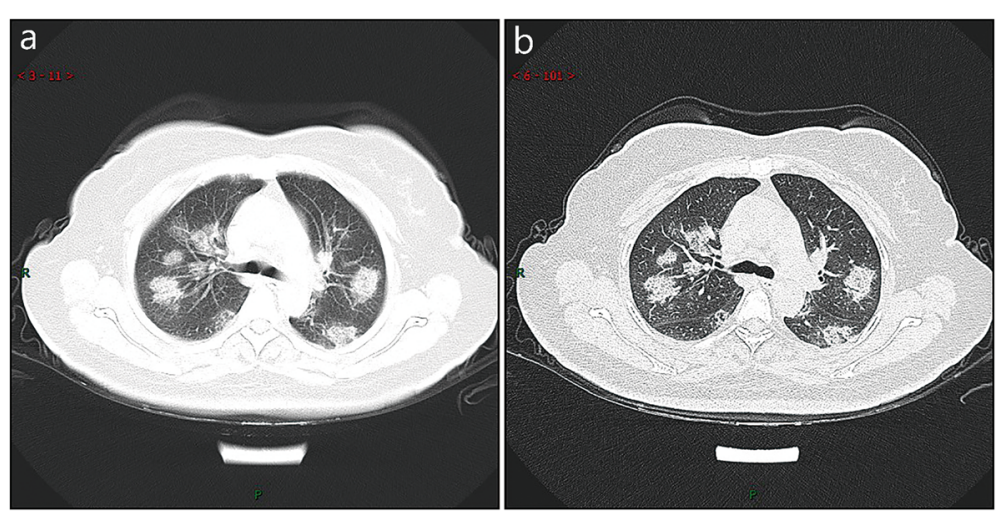

Fig. $8 \mathrm{CT}$ imaging of rapid progression stage. A 50 years old female with anorexia, fatigue, muscle soreness, nasal congestion and runny nose for 1 week, sore and itching throat for 2 days. Laboratory test: increased erythrocyte sedimentation rate $(25 \mathrm{~mm} / \mathrm{h})$, normal white blood cells $\left(4.08 \times 10^{9} / \mathrm{L}\right)$, decreased lymphocytes $\left(0.96 \times 10^{9} / \mathrm{L}\right)$, increased C-reaction protein $(60.8 \mathrm{mg} / \mathrm{L})$. Imaging examination: a (thin layer CT) and b (high-resolution CT) showed multiplepatchy and light consolidation in both lungs and grid-like thickness of interlobular septa 

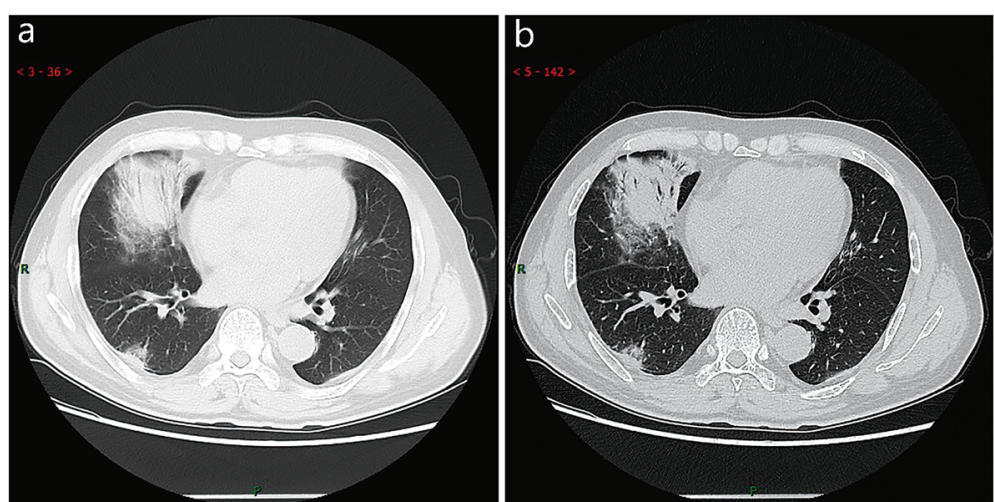

Fig. $9 \mathrm{CT}$ imaging of consolidation stage. A 65 years old male with fever (maximum temperature of $39^{\circ} \mathrm{C}$ ). Laboratory test: hypoproteinemia (decreased total protein $(62.20 \mathrm{~g} / \mathrm{L})$, decreased albumin $(35.70 \mathrm{~g} / \mathrm{L})$ ), abnormal liver function (increased alanine aminotransferase $(79 \mathrm{U} / \mathrm{L})$, increased aspartate aminotransferase $(72 \mathrm{U} / \mathrm{L}))$, increased procalcitonin $(0.10 \mathrm{ng} / \mathrm{ml})$, increased C-reaction protein $(53 \mathrm{mg} / \mathrm{L})$, decreased white blood cells $\left(3.72 \times 10^{9} / \mathrm{L}\right)$, decreased lymphocytes $\left(0.9 \times 10^{9} / \mathrm{L}\right)$, mildanemia (decreased red blood cells $\left(4.10 \times 10^{12} / \mathrm{L}\right)$, decreased hemoglobin $(131.10 \mathrm{~g} / \mathrm{L})$, decreased hematocrit (39.0\%). Imaging examination: a (thin layer CT) and $\mathbf{b}$ (high-resolution CT) showedmultiple patchyand large consolidation in right middle lobe, posterior and basal segment of right lower lobe and outer and basal segment of left lower lobe, with air-bronchogram inside

vessels. Detection of other inflammatory factors may help to preliminarily evaluate the immune status of patients.

\subsubsection{Clinical data from Zhongnan Hospital of Wuhan University}

In the early stage of this disease, the total number of leukocytes in peripheral blood was normal or decreased, and the lymphocyte count decreased. In some patients, liver enzyme (transaminase), creatine kinase (CK) and myoglobin increased. CRP, ESR, and IL-6 increased, and PCT was normal in most patients. The increased Ddimer occurred in severe cases.
The data from the first 38 patients with 2019-nCoV infection who hospitalized in Zhongnan Hospital of Wuhan University were collected. Analysis revealed that the average value of white blood cells (WBC) was $5.45(2.30$ $13.82) \times 10^{9} / \mathrm{L}, \quad$ PLT was $164.5(47-317) \times 10^{9} / \mathrm{L}$, lymphocyte was $0.87(0.24-2.27) \times 10^{9} / \mathrm{L}$, and monocyte was $0.38(0.12-0.62) \times 10^{9} / \mathrm{L}$. The average value of ALT (alanine aminotransferase) was $37.6(6-128) \mathrm{U} / \mathrm{L}$ and AST (aspartate aminotransferase) was $53.3(18-169)$ U/L. The average value of CK was $315(33-3051) \mathrm{U} / \mathrm{L}, \mathrm{ESR}$ was $29.3(8-67) \mathrm{mm} / \mathrm{h}$, CRP was $61.8(3-170.91) \mathrm{mg} / \mathrm{L}$, IL-6 was $57(3.1-134.4) \mathrm{pg} / \mathrm{ml}$, and D-dimer was $400(46-3330) \mathrm{ng} / \mathrm{ml}$.
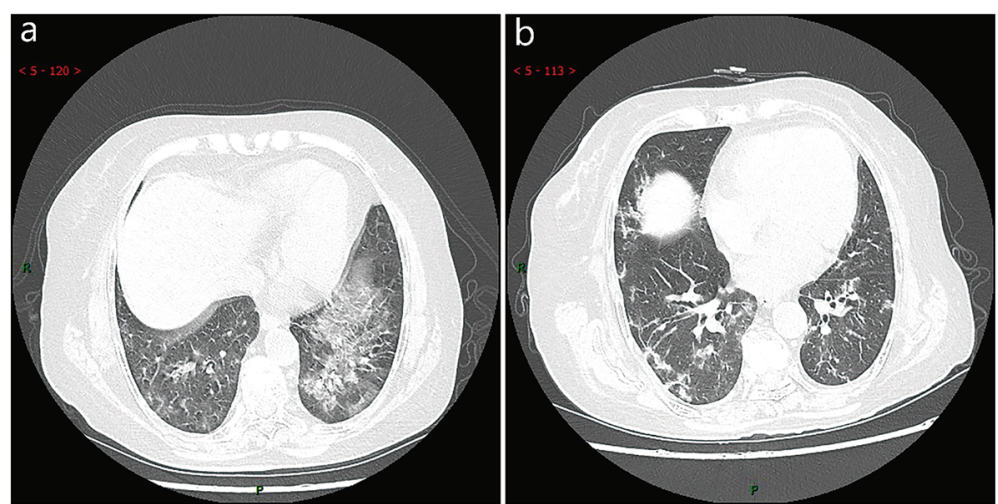

Fig. $10 \mathrm{CT}$ imaging of dissipation stage. A 79 years old female with intermittent fever. Laboratory test after 3 days of comprehensive treatment: decreased red blood cells $\left(3.73 \times 10^{12} / \mathrm{L}\right)$, hemoglobin $(107 \mathrm{~g} / \mathrm{L})$, decreased hematocrit $(31.8 \%)$, decreased lymphocytes percentage $(13.9 \%)$, decreased lymphocytes $\left(0.62 \times 10^{9} / \mathrm{L}\right)$, decreased eosinophil count percentage $(0 \%)$, decreased eosinophil count $\left(0 \times 10^{9} / \mathrm{L}\right)$, increased alanine aminotransferase $(46 \mathrm{U} / \mathrm{L})$, deceased total protein $(56.8 \mathrm{~g} / \mathrm{L})$, decreased albumin $(33.5 \mathrm{~g} / \mathrm{L})$, normal C-reaction protein and procalcitonin. Imaging examination: a patchy ground-glass opacity and grid-like thickening of interlobular septa in the tongue-like segment of left upper lobe, and patchy consolidation in the posterior segment of right middle and lower lobe. b 9 days after admission to hospotial, CT scan showed absorption of lesions in the middle lobe, narrowing of lesions in the lower lobe of the right lung, and absorption of lesions in the tongue-like segment of left upper lobe which exhibited a cord-like change 
Compared with 120 healthy check-ups, the absolute value of lymphocyte $(0.87$ vs 2.13$) \times 10^{9} / \mathrm{L}$, lymphocyte percentage (19.5\% vs $33.7 \%)$, eosinophil percentage $(0.13 \%$ vs $2.16 \%)$, and absolute value (0.0061 vs $0.1417) \times 10^{9} / \mathrm{L}$ in $2019-\mathrm{nCoV}$ patients were significantly reduced $(P<0.05)$. The absolute number $(4.2 \mathrm{vs}$ $3.7) \times 10^{9} / \mathrm{L}$ and the percentage $(72.0 \%$ vs $57.0 \%)$ increased in $2019-\mathrm{nCoV}$ patients $(P<0.05)$. The percentage of monocytes increased slightly ( $8.1 \%$ vs $6.8 \%)$, while the absolute number of monocytes did not change significantly $(0.38$ vs 0.44$) \times 10^{9} / \mathrm{L}$.

\subsection{Other early diagnosis methods}

The next generation sequencing (NGS) and electron microscope technology play a role in the early diagnosis, but their diagnostic values have been weakened by the discovery of specific nucleic acid detection technology. In addition, NGS detection can tell whether the pathogen has mutated or not.

\section{Treatment and control 6.1 Principles}

Suspected and confirmed cases need to be treated in designated hospitals with effective isolation and protection conditions. Suspected cases need to be treated separately in single room, confirmed cases are admitted to a same ward, and critical cases should be admitted to ICU as soon as possible.

\subsection{Treatment plans}

(1) The patient should rest in bed, being monitored for vital signs (heart rate, pulse oxygen saturation, respiratory rate, blood pressure) and given supportive treatment to ensure sufficient energy intake and balance for water, electrolytes, acidbase levels and other internal environment factors (Strong recommendation).

(2) The patient should be monitored for blood routine, CRP, PCT, organ function (liver enzyme, bilirubin, myocardial enzyme, creatinine, urea nitrogen, Urine volume, etc.), coagulation function, arterial blood gas analysis and chest imaging (Strong recommendation).

(3) The patient should be given effective oxygen therapy, including nasal catheter, mask oxygen, high flow nasal oxygen therapy (HFNO), non-invasive ventilation (NIV) or invasive mechanical ventilation (Strong recommendation).

First, oxygen therapy is the choice for patients with severe respiratory infections, respiratory distress, hypoxemia or shock. The initial flow rate is $5 \mathrm{~L} / \mathrm{min}$, and the titration flow rate is to reach the target oxygen saturation (adults: $\mathrm{SpO}_{2} \geq 90 \%$ in non-pregnant patients, $\mathrm{SpO}_{2} \geq 92-95 \%$ in pregnant patients; children: $\mathrm{SpO}_{2} \geq$ $94 \%$ in children with obstructive dyspnea, apnea, severe respiratory distress, central cyanosis, shock, coma or convulsions, and $\geq 90 \%$ in other children).

Second, respiratory support should be given to patients with hypoxic respiratory failure and acute respiratory distress syndrome. HFNO or NIV can be selected when nasal cannula or mask oxygen therapy was ineffective or the patient had hypoxic respiratory failure. However, when patients had hypercapnia (acute exacerbation of chronic obstructive pulmonary disease, cardiogenic pulmonary edema), hemodynamic instability, multiple organ failure, and abnormal mental status HFNO oxygen is not the routinely adopted measure. If respiratory failure cannot be improved or worsens continuously within a short time $(1 \mathrm{~h})$ after using HFNO or NIV, intubation should be performed immediately. Low tidal volume $(4-8 \mathrm{ml} / \mathrm{kg}$ ) and low suction pressure (platform pressure $<30 \mathrm{cmH}_{2} \mathrm{O}$ ) are used for invasive mechanical ventilation. It is suggested that positive endexpiratory pressure (PEEP) with high positive endexpiratory pressure should be used in patients with moderate or severe acute respiratory distress syndrome, and PEEP should be titrated according to $\mathrm{FiO}_{2}$ to maintain $\mathrm{SpO}_{2}$, in order to improve alveolar atelectasis and reduce alveolar hyper-expansion and pulmonary vascular resistance at the end of inspiration. For severe patients with ARDS, it is recommended to ventilate in prone position for more than $12 \mathrm{~h} / \mathrm{d}$.

(4) Extracorporeal Membrane Oxygenation (ECMO) should be considered for the patients with refractory hypoxemia that is difficult to be corrected by protective lung ventilation. (Strong recommendation).

\subsection{Drug treatment \\ 6.3.1 Antiviral treatment}

(1) At present, there is no evidence from RCT to support specific drug treatment against the new coronavirus in suspected or confirmed cases.

(2) The $\alpha$-interferon atomization inhalation can be considered (5 million $\mathrm{U}$ per time for adults in sterile injection water, twice a day) (Weak recommendation); lopinavir/ritonavir orally, 2 capsules each time, twice a day, can be also considered (Weak recommendation).

Low-level evidences included retrospective cohort, historically controlled studies, case reports, and case series revealed that lopinavir/ritonavir alone or in combination with antivirals produced certain benefits in the 
treatment of SARS and MERS, such as reducing the incidence or mortality of ARDS [26-29]. A recently systematic review showed that lopinavir/ritonavir's anti-coronavirus effect was mainly seen in its early application, for reducing patient mortality and reduced glucocorticoid consumption. However, if the early treatment window is missed, there will be no significant effect in their late application [30]. Real-world study stills need to further explore the clinical effects of its early use in 2019-nCoV infected pneumonia.

The effectiveness of the combined use of antivirals is still controversial [31-34].

\subsubsection{Antibiotic therapy}

(1) Principles. Avoid blind or inappropriate use of antibacterial drugs, especially the combination of broad-spectrum antibacterial drugs. Enhancement of bacteriological surveillance should be performed and promptly given appropriate antibacterial drugs when it occurs secondary bacterial infection.

(2) According to the clinical manifestations of patients, if the accompanying bacterial infection cannot be ruled out, mild patients can take antibacterial drugs against community-acquired pneumonia, such as amoxicillin, azithromycin, or fluoroquinolones; empirical antibacterial treatment in severe patients should cover all possible pathogens, deescalating therapy until the pathogenic bacteria are clarified.

\subsubsection{Corticosteroid therapy}

The use of corticosteroids for severe ARDS is controversial; therefore, systemic use of glucocorticoids needs to be cautious. Methylprednisolone can be used as appropriate for patients with rapid disease progression or severe illness. According to the severity of the disease, 40 to $80 \mathrm{mg}$ of methylprednisolone per day can be considered, and the total daily dose should not exceed $2 \mathrm{mg} / \mathrm{kg}$ (Weak recommendation).

SARS management related researches showed that timely use of non-invasive continuous positive airway pressure and corticosteroids is an effective strategy for increased lung shadows and increased dyspnea. Appropriate use of glucocorticoids is able to significantly improve the clinical symptoms of patients with SARS, reduce the degree of disease progression, and accelerate the absorption of lung lesions; but it cannot shorten the length of hospital stay $[35,36]$. Be cautious that hormone therapy has some incidence of adverse reactions [37].

\subsubsection{Other medications}

(1) Symptomatic treatment of fever. When the temperature is higher than $38.5^{\circ} \mathrm{C}$, ibuprofen can be used for antipyretic (oral, $0.2 \mathrm{~g}$ per time, it can be used every 4-6 h in continuous fever, but no more than 4 times in $24 \mathrm{~h}$ ), and the temperature below $38^{\circ} \mathrm{C}$ is acceptable. Much lower body temperature is not conducive to antiviral treatment.

(2) Nutrition support treatment. Inpatients are screened for nutrition risk based on the NRS2002 score when they are admitted to the hospital. The recommended plan for patients with different nutrition risk scores are as follows:

First, if the total score is $<3$ points, it is recommended to eat protein-rich foods (such as eggs, fish, lean meat, dairy products) and carbohydratecontaining diets. The supposed ideal energy intake is $25-30 \mathrm{kcal} /(\mathrm{kg} \cdot \mathrm{d})$ and the protein mass are $1.5 \mathrm{~g} /(\mathrm{kg} \cdot \mathrm{d})$.

Second, if the total score is $\geq 3$ points, the patient should be given nutritional support as early as possible. It is recommended to increase protein intake by oral nutrition supplement, 2-3 times/day $(\geq 18 \mathrm{~g}$ protein/time). In order to reach the mount of $18 \mathrm{~g}$ protein/time, protein powder can be added on the basis of standard whole protein preparations. Enteral nutrition tube should to be placed when the patient cannot intake supplemental nutrition by oral routine.

(3) Reduce the incidence of stress ulcers and gastrointestinal bleeding. Use $\mathrm{H}_{2}$ receptor antagonists or proton pump inhibitors in patients with gastrointestinal bleeding risk factors. The risk factors for gastrointestinal bleeding include mechanical ventilation $\geq 48 \mathrm{~h}$, coagulation dysfunction, renal replacement therapy, liver disease, various complications, and a higher score of organ failure.

(4) Reduce the secretion of lung glands and improve the respiratory function. For patients with dyspnea, cough, wheeze, and respiratory distress syndrome due to the increased respiratory gland secretion, it is recommended to use selective (M1, M3) receptor anticholinergic drugs to reduce the secretion, relax the smooth muscle in airway, relieve airway spasm and improve the pulmonary ventilation.

(5) Reduce the incidence of venous embolism. Evaluate the risk of venous embolism in patients and use low-molecular-weight heparin or heparin in highrisk patients without contraindications.

\subsection{Traditional Chinese medicine treatment 6.4.1 Guiding principles}

Treat the patient based on syndrome differentiation individually. Prevention before illness is better than treatment after getting diseased. 


\subsubsection{Prevention}

(1) Community. Implement relevant national regulations and take great effort to keep away from contaminated materials, disinfect the environment, and improve the healthcare management.

(2) Individual. It is recommended to take food in proper amount and balanced nutrition, have regular daily life and physical activities, and avoid overloaded work.

(3) Psychology. Develop proper interests and career in a mutual promoting manner.

(4) Drug. Including:

i Fumigation with moxa in the room, $1-5 \mathrm{~g} / \mathrm{m}^{2}$ for 30 min per day.

ii Wearing perfumed Chinese herb bags (clove, fineleaf schizonepeta herb, Perilla frutescens, atractylodes lancea, cinnamon, biond magnolia flower, asarum sieboldii, and Elettaria cardamomum, $2 \mathrm{~g}$ for each, crushed into powder and put it into bags for external use, change a new one every 10 days).

iii Prescription of Chinese herbs for feet bath (vulgaris $10 \mathrm{~g}$, carthamus $10 \mathrm{~g}$, and dried ginger $6 \mathrm{~g})$ Soaking the herbs in boiling water and bath the feet into the medical liquid when the temperature is suitable. Soak feet for about $20 \mathrm{~min}$

iv Prescription of Chinese herbs for prophylaxis: Astragalus mongholicus $12 \mathrm{~g}$, roasted rhizoma atractylodis macrocephalae $10 \mathrm{~g}$, saposhnikovia divaricata $10 \mathrm{~g}$, Cyrtomium fortunei $10 \mathrm{~g}$, honeysuckle $10 \mathrm{~g}$, dried tangerine or orange peel $6 \mathrm{~g}$, eupatorium $10 \mathrm{~g}$, and licorice $10 \mathrm{~g}$. Taking the medicine above yielded decoction once a day for adults, and for 5 days as a treatment course. If for children, cutting the dose to half.

$\mathrm{v}$ Medical tea: perilla leaf $6 \mathrm{~g}$, agastache leaf $6 \mathrm{~g}$, dried tangerine or orange peel $9 \mathrm{~g}$, stewed amomum tsao-ko $6 \mathrm{~g}$, and 3 slices of ginger. Soak the herbs in hot water and drink the water just like enjoying the tea.

vi Chinese patent medicine: Huoxiang Zhengqi capsule or Huoxiang Zhengqi Shui (in half dose).

\subsubsection{Treatment [12]}

In medical observation period There are two clinical symptoms in this period, including:

(1) Clinical symptoms 1: hypodynamia accompanied by gastrointestinal upset. And the recommended Chinese patent medicine is the Huoxiang Zhengqi capsules (ball, liquid, or oral liquid).
(2) Clinical symptoms 2: hypodynamia and fever. And the recommended Chinese patent medicines is the Jinhua Qinggan granules, Lianhua Qingwen capsules (granules), Shufeng Jiedu capsules (granules), or Fangfeng Tongsheng pills (granules).

Clinical treatment period This period involving 7 stages, including:

(1) Early-stage, characterized as exterior syndrome of cold-dampness. In this stage, the clinical manifestations presents as follow: aversion to cold without sweating, headache and generalized heaviness, limb pain, glomus and fullness in the chest and diaphragm, thirst with no desire to drink, ungratifying loose stool, yellow urine, frequent micturition and yellow urine. The therapeutic logic is to dissipate cold and eliminate dampness. And the recommended prescription is the Huoxiang Zhengqi powder (Yin dampness injuring superficies case from the National Famous Traditional Chinese Medical Doctor Medical Cases); which comprises of perilla leaf $10 \mathrm{~g}$, atractylodes lancea $15 \mathrm{~g}$, radix angelicae dahuricae $10 \mathrm{~g}$, dried tangerine or orange peel $10 \mathrm{~g}$, notopterygium root $10 \mathrm{~g}$, agastache rugosus $10 \mathrm{~g}$ (end addition), mangnolia officinalis $10 \mathrm{~g}$, saposhnikovia divaricata $10 \mathrm{~g}$, poria peel $15 \mathrm{~g}$, and Tetrapanax papyriferus $10 \mathrm{~g}$ above yielded decoction. In addition, the recommended Chinese patent medicine is Huoxiang Zhengqi capsules or Huoxiang Zhengqi Shui.

(2) Early-stage, characterized as cold-dampness obstructing lung. In this stage, the clinical manifestations presents as follow: aversion to cold with or without fever, dry cough, dry throat, fatigue and hypodynamia, oppression in chest, epigastric fullness, or nausea, loose stool. The tongue is pale or reddish, the tongue fur is slimy white, and soggy pulse. Hence, the therapeutic logic is to dissipate cold and resolve obstruction. And the recommended prescriptions comprises of atractylodes lancea $15 \mathrm{~g}$, dried tangerine or orange peel $10 \mathrm{~g}$, mangnolia officinalis $10 \mathrm{~g}$, agastache rugosus $10 \mathrm{~g}$ (end addition), amomum tsao-ko $6 \mathrm{~g}$, ephedra herb $6 \mathrm{~g}$, notopterygium root $10 \mathrm{~g}$, ginger $10 \mathrm{~g}$, areca-nut $10 \mathrm{~g}$ (end addition), periostracum cicada $10 \mathrm{~g}$, bombyx batryticatus $10 \mathrm{~g}$, and rhizoma curcumae longae $10 \mathrm{~g}$ above yielded decoction.

(3) Middle-stage, characterized as epidemic toxin blocking the lung. In this stage, its clinical manifestations includes persistent fever or alternating cold and heat, cough with less phlegm, or yellow phlegm, abdominal distension and constipation; oppression in chest with anhelation, cough with wheezes, panting on 
exertion; or red tongue, slimy yellow fur or yellow dry fur, slippery and rapid pulse. Therefore, the therapeutic logic is clearing heat and detoxicating. And the recommended prescription comprises of almond $10 \mathrm{~g}$, gypsum $30 \mathrm{~g}$ (predecoction), trichosanthes kirilowii $30 \mathrm{~g}$, rhubarb $6 \mathrm{~g}$ (end addition), ephedra with honey fried $6 \mathrm{~g}$, semen lepidii $10 \mathrm{~g}$, peach kernel $10 \mathrm{~g}$, amomum tsao-ko $6 \mathrm{~g}$, arecanut $10 \mathrm{~g}$, and atractylodes lancea $10 \mathrm{~g}$ above yielded decoction.

In addition, the recommended Chinese patent medicine is Xiyanping injection or Xuebijing injection.

(4) Severe stage, characterized as heat toxin generating stasis. In this stage, the clinical manifestations is known as high fever, oppression in chest with anhelation, purple-black facial complexion, lips dark and swollen, obnubilation, crimson tongue, yellow dry fur, surging and fine rapid stringlike pulse. Thus, its therapeutic logic is detoxicating and dispersing blood stasis.

The recommended prescription is three Yellows and Gypsum decoction, Shang Jiang Powder, and Toxin-Resolving Blood-quickening decoction. Its composition comprises of ephedra with honey fried $10 \mathrm{~g}$, almond $10 \mathrm{~g}$, gypsum 20-30 g, periostracum cicada $10 \mathrm{~g}$, bombyx batryticatus $10 \mathrm{~g}$, rhizoma curcumae longae $10 \mathrm{~g}$, rhubarb stir-fried with wine $10 \mathrm{~g}$, scutellaria baicalensis $10 \mathrm{~g}$, coptis chinensis $5 \mathrm{~g}$, phillyrin $15 \mathrm{~g}$, angelica sinensis $10 \mathrm{~g}$, peach kernel $10 \mathrm{~g}$, radix paeoniae rubra $15 \mathrm{~g}$, and rhizome of rehmannia $15 \mathrm{~g}$ above yielded decoction.

The recommended Chinese patent medicines is the Xiyanping injection, Xuebijing injection, Qingkailing injection, or Angong Niuhuang pills.

(5) Severe-stage, characterized as inner blocking causing collapse. In this stage, the clinical manifestations include dyspnea, panting on exertion or need assisted ventilation, accompanied by coma, and agitation, cold limbs with cold sweating, dark purple tongue, thick or dry thick tongue fur, floating and rootless pulse. The thrapeutic logic is rescuing from collapse by restoring Yang. Hence, the recommended prescription comprises of ginseng $15 \mathrm{~g}$, aconitine $10 \mathrm{~g}$ (predecoction), and Cornus officinalis $15 \mathrm{~g}$ above yielded decoction, and both taken with fluid Suhexiang pills or Angong Niuhuang pills.

The recommended Chinese patent medicines is Xuebijing injection, Shenfu injection, or Shengmai injection.

(6) Recovery-stage, presents as lung and spleen Qi deficiency. Its clinical manifestations include shortness of breath, fatigue and hypodynamia, anorexia, nausea and vomiting, glomus and fullness, weak stools, ungratifying loose stool, pale tender-soft enlarged tongue, slimy white tongue fur. Therefore, therapeutic logic is to supplement the spleen and lung.

The recommended prescription comprises of rhizoma pinellinae praeparata $9 \mathrm{~g}$, dried tangerine or orange peel $10 \mathrm{~g}$, Codonopsis pilosula $15 \mathrm{~g}$, radix astragali preparata $30 \mathrm{~g}$, poria cocos $15 \mathrm{~g}$, agastache rugosus $10 \mathrm{~g}$, and fructus amomi $6 \mathrm{~g}$ (end addition) above yielded decoction. In addition, the recommended Chinese patent medicines is pill of costus and amomum with six noble ingredients.

(7) Recovery-stage, characterized as deficiency of Qi and Yin. The clinical manifestations of this stage is generalized heat with sweating, chest heat vexation, Qi counterflow with retching and vomiting, shortness of breath and lassitude of essence-spirit, red tongue and thin tongue fur, vacuous pulse. Hence, the therapeutic logics is boost Qi and nourish Yin.

The recommended prescription is Zhuye Shigao decoction with cogongrass rhizome and rhizoma phragmitis; and the composition of this prescription includes bamboo leaf $15 \mathrm{~g}$, gypsum $15 \mathrm{~g}$ (predecoction), Codonopsis pilosula $15 \mathrm{~g}$, radix ophiopogonis $10 \mathrm{~g}$, pinellia ternate $9 \mathrm{~g}$, cogongrass rhizome 15-30 g, rhizoma phragmitis $20 \mathrm{~g}$, licorice $10 \mathrm{~g}$, and polished round-grained rice $30 \mathrm{~g}$ above yielded decoction.

The recommended Chinese patent medicine: Shengmaiyin.

\subsection{Treatment of severe patients}

\subsubsection{Hypoxemic respiratory failure and ARDS treatments}

Treatment principle: treat the patients to improve the symptoms and underlying diseases, actively prevent potential complications and secondary infection; provide timely measures to support organ function.

(1) Hypoxic respiratory failure and severe ARDS. Give oxygen therapy immediately to patients with ARDS, and closely monitor them for signs of clinical deterioration, such as rapidly progressive respiratory failure. Consider severe hypoxemic respiratory failure when standard oxygen therapy fails. When patients have increased frequency of breathing ( $>30$ times $/ \mathrm{min}$ ) and hypoxemia $\left(\mathrm{SpO}_{2}<90 \%\right.$ or $\left.\mathrm{PaO}_{2}<60 \mathrm{mmHg}\right)$ even with oxygen delivered via a face mask and reservoir bag (gas flow of $10 \sim 15 \mathrm{~L} / \mathrm{min}, \mathrm{FiO}_{2}$ $0.60-0.95)$, it may be considered as hypoxic respiratory failure.

ARDS is a status of severe acute hypoxic respiratory failure caused by increased pulmonary capillary permeability and alveolar epithelial cell damage. It can be divided into mild, moderate and severe 
Table 6 The Berlin definition for acute respiratory distress syndrome

\begin{tabular}{|c|c|c|c|}
\hline Item & Mild & Moderate & Severe \\
\hline Onset time & \multicolumn{3}{|c|}{ Respiratory symptoms developed/aggravated within 1 week after clinically known damage } \\
\hline Hypoxemia & $\begin{array}{l}\mathrm{PaO}_{2} / \mathrm{FiO}_{2} 201-300 \mathrm{mmHg} \text {, } \\
\text { PEEP or CPAP } \geq 5 \mathrm{cmH}_{2} \mathrm{O}\end{array}$ & $\begin{array}{l}\mathrm{PaO}_{2} / \mathrm{FiO}_{2} \quad 101-200 \mathrm{mmHg} \text {, } \\
\mathrm{PEEP} \geq 5 \mathrm{cmH}_{2} \mathrm{O}\end{array}$ & $\begin{array}{l}\mathrm{PaO}_{2} / \mathrm{FiO}_{2} \leq 100 \mathrm{mmHg} \\
\mathrm{PEEP} \geq 10 \mathrm{cmH}_{2} \mathrm{O}\end{array}$ \\
\hline Causes of pulmonary edema & \multicolumn{3}{|c|}{$\begin{array}{l}\text { Respiratory failure cannot be completely explained by heart failure or fluid overload. Objective assessment } \\
\text { (such as echocardiography) is needed to eliminate the possibility of hydrostatic pulmonary edema if other } \\
\text { risk factor is absent. }\end{array}$} \\
\hline Abnormality in imaging & \multicolumn{3}{|c|}{ Decreased transparence of two lungs cannot be completely explained by pleural effusion, atelectasis or nodules } \\
\hline
\end{tabular}

PEEP positive end-expiratory pressure, CPAP continuous positive airway pressure

conditions according to the Berlin definition [38] (Table 6).

(2) HFNO. Under the support of standard oxygen therapy, to maintain $\mathrm{SpO}_{2}$ above $93 \%$ stills hard, and the breathing rate increases rapidly, then HFNO should be considered. HFNO can deliver $60 \mathrm{~L} / \mathrm{min}$ of gas flow and $\mathrm{FiO}_{2}$ up to 1.0. Generally, gas flow is initially set as $30-40 \mathrm{~L} / \mathrm{min}$ and oxygen concentration $50 \%-60 \%$, which is well tolerated and coordinated. Then settings can be adjusted according to the oxygenation status of patients. Compared with standard oxygen therapy, HFNO is able to reduce the chance of tracheal intubation. Patients with hypercapnia (like exacerbation of obstructive lung disease, cardiogenic pulmonary edema), hemodynamic instability, multi-organ failure, or abnormal mental status should not be given HFNO. HFNO may be safe in patients with mild-moderate and non-worsening hypercapnia. However, if the respiratory distress still exists or even worsens dramatically under $\mathrm{HFNO}\left(\mathrm{FiO}_{2}>70 \%\right.$, gas flow $>50 \mathrm{~L} / \mathrm{min}$ for 1 hour), the respiratory supporting strategy should be changed.

(3) NIV. NIV provides a certain positive pressure ventilation effect through the positive pressure formed by the closed mask. HFNO combined with intermittent short-term NIV (1-2h) support may be useful to reduce respiratory power consumption and improve oxygenation. But NIV guidelines recommend the use of respiratory support therapy in hypoxemic respiratory failure or pandemic viral illness. Limited data showed a high failure rate of NIV in MERS patients. Invasive mechanical ventilation should be considered in case the ARDS still exists and even acutely deteriorates in NIV process (about $1 \mathrm{~h}$ ). Patients with hemodynamic instability, multiple organ failure, or abnormal mental status should not receive NIV.

(4) Invasive mechanical ventilation. Under the support of $\mathrm{HFNO}$ (the demand for $\mathrm{FiO}_{2}>70 \%$ and gas flow $>50 \mathrm{~L} / \mathrm{min}$ ) or NIV, ARDS still exists and even acutely deteriorates, invasive mechanical ventilation should be implemented as soon as possible.
Endotracheal intubation should be carried out by trained and experienced provider using airborne precautions, since endotracheal intubation is an operation that may produce a large number of contagious aerosols.

The strategy of protective lung ventilation should be implemented in invasive mechanical ventilation: lower tidal volume (4-6 ml $/ \mathrm{kg})$, lower plateau pressure $\left(<30 \mathrm{cmH}_{2} \mathrm{O}\right)$, and appropriate PEEP. For patients with moderate-severe ARDS $\left(\mathrm{PaO}_{2} / \mathrm{FiO}_{2}<150\right)$, it is recommended to use higher PEEP, apply prone ventilation for more than $12 \mathrm{~h}$ per day and adopt deep sedation and analgesia muscle relaxation strategy within the first $48 \mathrm{~h}$ of mechanical ventilation. For patients with severe acute hypoxic respiratory failure, we should pay attention to and prevent ventilator-associated lung injury after mechanical ventilation.

(5) Extracorporeal Life Support (ECLS). In the process of invasive mechanical ventilation when the patient is still in the state of hypoxia, combined with increased partial pressure of carbon dioxide (excluding ventilation dysfunction, $\mathrm{PaCO}_{2}>60 \mathrm{mmHg}$ ), especially after muscle relaxation and prone ventilation, it is necessary to consider to implement ECLS. However, it is suggested that ECLS treatment should only be carried out under the condition that the professional center is with access to expertise. Currently the ECLS in ICU includes VV-ECMO (blood is pumped from femoral vein, and returns to right atrium through internal jugular vein after oxygenation through membrane oxygenator) and VA-ECMO (blood is pumped from femoral vein and directly enters aortic system through femoral artery after oxygenation through membrane oxygenator). For patients with severe refractory hypoxemia, neuromuscular blockade can improve oxygen supply, especially if there is still evidence of ventilator-patient dyssynchrony after the use of sedatives. However, neuromuscular blockade through continuous infusion should not be routinely used in patients with moderate-severe ARDS; Where available, ECMO in conjunction with low tidal-volume mechanical 
ventilation can be considered in the treatment of patients with severe refractory hypoxemia in whom standard therapy are failing; Routine use of highfrequency oscillatory ventilation (HFOV) in patients with moderate-severe ARDS is not beneficial, but may be harmful. However, HFOV may still be regarded as a rescue therapy for patients with severe ARDS and refractory hypoxemia. ECMO can be used in some severe ARDS patients (lung injury score $>3$ or $\mathrm{pH}<7.2$ due to uncompensated hypercapnia), but it is not recommended for all ARDS patients. It can be considered to use extracorporeal carbon dioxide removal for ARDS patients, if there is more supportive research evidence in the future.

Conservative fluid management can be adopted for ARDS patients without tissue hypoperfusion. Use vasoactive drugs to improve microcirculation. Empirical antibiotics targeting the suspected potential infection should be used as soon as possible, blind or improper combination of broad-spectrum antibiotics should be avoided. Unless for special reasons, the routine use of corticosteroids should be avoided. Glucocorticoids can be used in a short time (3-5 days) according to the degree of dyspnea and the progress of chest imaging if appropriate and the recommended dose is not more than the equivalent to $1-2 \mathrm{mg} / \mathrm{kg}$ methylprednisone per day. Provide intensive standard supportive care to the critically ill patients, including prevention of deep vein thrombosis and stress-induced gastrointestinal bleeding, blood glucose control and so on. Enteral nutrition can be provided. Supplemental nutrition with omega-3 fatty acids and antioxidants is not recommended. Inhaled or intravenous beta-adrenergic agonists are not recommended to promote alveolar fluid clearance and resolution of pulmonary edema.

\subsubsection{Treatment of septic shock}

(1) Recognize the septic shock. When infection is suspected or confirmed, and on the basis of full fluid resuscitation, vasoconstrictor drugs are still needed to maintain mean arterial pressure (MAP) $\geq 65 \mathrm{mmHg}$ with lactate $\geq 2 \mathrm{mmol} / \mathrm{L}$, the existence of septic shock should be considered. If lactate cannot be monitored for some reasons, the following three manifestations (changes in mental state, oliguria, poor peripheral perfusion and prolonged capillary filling time) should be considered as signs of a combination of infection and hypoperfusion.

(2) In resuscitation from septic shock in adults, at least $30 \mathrm{ml} / \mathrm{kg}$ of isotonic crystalloid was considered for adults in the first $3 \mathrm{~h}$. In resuscitation from septic shock in children, give $20 \mathrm{ml} / \mathrm{kg}$ as a rapid bolus and up to $40-60 \mathrm{ml} / \mathrm{kg}$ in first aid.

(3) Isosmotic crystal solution is recommended for resuscitation. Do not use hypotonic crystalloids, starches, or gelatins for resuscitation in the first hour. Albumin may be considered as a resuscitation fluid, but this recommendation was based on low- quality evidence under certain conditions.

(4) Administer vasoconstrictor is suggested when shock persists after fluid resuscitation, noradrenaline as the first choice. The initial blood pressure target is MAP $\geq 65 \mathrm{mmHg}$ in adults and age-appropriate targets in children.

(5) If it is not possible to place a central venous catheter, vasopressors can be infused through the peripheral vein through large vein and signs of extravasation and local tissue necrosis should be closely monitored.

(6) If extravasation occurs, stop infusion. Vasopressors can also be administered via intraosseous needles.

\subsection{Condition evaluation and treatment effect evaluation 6.6.1 Criteria to withdraw ECLS}

(1) Remove VV-ECMO. The oxygen concentration of the ECMO air-oxygen mixer has dropped to $21 \%$, the air flow rate has dropped to 0 , and the ventilator is not strong enough. Lasting for $2-3 \mathrm{~h}$, the respiratory rate is within 25 breaths $/ \mathrm{min}$, $\mathrm{SpO}_{2}>92 \%, \mathrm{PaCO}_{2}$ is normal, and withdrawal from VV-ECMO may be considered.

(2) Remove VA-ECMO. The blood flow rate is reduced to the rate of $(0.2$ to $0.5 \mathrm{~L} / \mathrm{min})$ every 5 to $6 \mathrm{~h}$ from $3 \mathrm{~L} / \mathrm{min}$, and the hemodynamic condition is stable. The blood flow rate is reduced to $1.5 \mathrm{~L} / \mathrm{min}$ within $24 \mathrm{~h}$. If there is a bridging tube, the arteriovenous end can be connected with a bridging tube to form an ECMO circuit for self-circulation, so that the body's hemodynamics is driven by the heart. If hemodynamics is stable for at least $6 \mathrm{~h}$, consider removing the machine.

\subsubsection{Criteria for removing invasive breathing}

When the patient is well aware, cough reflexes are obvious when sucking the sputum, the hemodynamics is stable, and the ventilator parameters are close to offline parameters, the spontaneous breathing test (SBT) is performed. After the SBT is passed, invasive breathing can be considered to remove the endotracheal tube.

\subsubsection{Standards of transfer out of ICU}

Patients do not need advanced respiratory support (HFNO, NIV, MV, ECLS, etc.); stable hemodynamics and tissue perfusion; no significant impairment of organ 
function; and no need for organ support treatment (CRRT, artificial liver, etc.). Consider transferring the patient out of ICU procedure.

\subsection{Discharge standards}

The body temperature returned to normal for more than 3 days; respiratory symptoms improved significantly; inflammation of the lungs showed obvious signs of absorption; and respiratory nucleic acid was negative for two consecutive times (one-day sampling time interval at least); and the patient can be released from isolation.

\section{Prevent and control nosocomial infection}

\subsection{Restriction and isolation guidelines for patient/} suspected patients

See Table 7. (Strong recommendation).

\subsection{Personal protection guidelines}

According to the principles of standard prevention and tertiary protection, all personnel entering various zones should be evaluated using individual inventory tables according to the exposure risk level. Chose personal protective equipment of various levels is necessary. Personal protective equipment should be worn strictly in accordance with the instructions and only used for one time (Table 8, Strong recommendation).

\section{Disease nursing}

8.1 Nursing of isolated patients at home

The patient's home isolation scheme is shown in Table 5.

Patients should monitor their body temperature and illness at home. If your body temperature continues to be higher than $38{ }^{\circ} \mathrm{C}$, or your breath is getting worse, you should seek medical treatment timely.

In addition to taking protective measures, the home caregivers also should monitor their body temperature closely.

\subsection{Nursing the patients}

\subsubsection{Nursing of oxygen therapy}

Mild patients generally use a nasal catheter and a mask for oxygen. Adjust the oxygen flow as appropriate according to the patient's condition and doctor's instruction, and

Table 7 Restriction and isolation guidelines checklist for patients/suspected cases (Strong recommendation)

\begin{tabular}{ll}
\hline Category & Tactics \\
\hline Environmental requirements & $\begin{array}{l}\text { 1.There should be clean areas, potential } \\
\text { contaminated areas, contaminated areas, } \\
\text { contaminated channels and clean channel }\end{array}$ \\
& \\
2. Isolation in single (priority strategy) \\
Collective isolation for the confirmed \\
patients, collective isolation for the \\
suspected cases (alternative strategy)
\end{tabular}

Requirements to the patient/ suspected Patient
5. Restrict the range of patient/suspected patient for their activities.
3. Ensure that the environment and articles are clean and disinfected

4. Proper medical waste management

Requirements to the medical staff request
6. Medical personnel enter the isolation area with proper self-protection through designated channels.

Precautions in practice

1.1 clearly arrange and mark the 3 areas

and transport materials or move from

clean area to contaminated area.

Retrograde is not allowed.

1.2 Each area should be physically partitioned and clearly marked

$2.1<4$ persons per isolation ward, bed spacing $\geq 1.1 \mathrm{~m}$

2.2 Equipped with separate toilet

2.3 Equipped with hand-cleaning and disinfection apparatus

2.4 Minimize the unnecessary items (e.g. remove the curtains, etc.)

3.1 Follow the Disinfection Guidelines checklist

3.2 Exclusive use of articles in isolation areas

4.1 The medical waste should be put in sealed double-layer yellow medical waste bags for regulated disposal procedure.

5.1 No escort or minimize the number of escorts.

5.2 Clear route for patient transport (get in or out through contaminated channels)

5.3 Patients going out should wear N95 masks or surgical masks

5.4 Follow the disinfection guidelines after being discharged from hospital.

6.1 Medical staff should perform the personal protection practice under the Personal Protection Guidelines in Table 8 
Table 8 Personal protection guidelines checklist (Strong recommendation)

\begin{tabular}{|c|c|c|c|c|c|c|c|c|c|c|}
\hline \multirow[t]{2}{*}{ Item } & \multirow{2}{*}{$\begin{array}{l}\text { Exposure } \\
\text { intensity of } \\
\text { infection risk }\end{array}$} & \multicolumn{9}{|c|}{ Protective measurement } \\
\hline & & $\begin{array}{l}\text { Round } \\
\text { hat }\end{array}$ & $\begin{array}{l}\text { N95 } \\
\text { mask }\end{array}$ & Coverall & $\begin{array}{l}\text { Eye protector/ } \\
\text { Protective panel }\end{array}$ & $\begin{array}{l}\text { Latex } \\
\text { gloves }\end{array}$ & $\begin{array}{l}\text { Barrier } \\
\text { gown }\end{array}$ & $\begin{array}{l}\text { Protective } \\
\text { clothing }\end{array}$ & $\begin{array}{l}\text { Shoe cover/ } \\
\text { Bootstrap }\end{array}$ & $\begin{array}{l}\text { Comprehensive } \\
\text { respiratory apparatus }\end{array}$ \\
\hline \multicolumn{11}{|c|}{ Recommendations as per work area } \\
\hline Pre-examination triage & Low & $\checkmark$ & $\checkmark$ & $\checkmark$ & & $\checkmark$ & $\checkmark$ & & & \\
\hline $\begin{array}{l}\text { General out-patient } \\
\text { service }\end{array}$ & Low & $\checkmark$ & $\checkmark$ & $\checkmark$ & & $\checkmark$ & & & & \\
\hline \multirow[t]{2}{*}{ General ward } & Medium & $\checkmark$ & $\checkmark$ & $\checkmark$ & $\checkmark$ & $\checkmark$ & $\checkmark$ & & & \\
\hline & High & $\checkmark$ & $\checkmark$ & $\checkmark$ & $\checkmark$ & $\checkmark$ & $\checkmark$ & $\checkmark$ & & \\
\hline \multirow[t]{2}{*}{ Fever clinic } & Medium & $\checkmark$ & $\checkmark$ & $\checkmark$ & $\checkmark$ & $\checkmark$ & $\checkmark$ & $\checkmark$ & $\checkmark$ & \\
\hline & High & $\checkmark$ & $\checkmark$ & $\checkmark$ & $\checkmark$ & $\checkmark$ & $\checkmark$ & $\checkmark$ & $\checkmark$ & $\checkmark$ \\
\hline \multirow[t]{2}{*}{ Isolation room (Area) } & Medium & $\checkmark$ & $\checkmark$ & $\checkmark$ & $\checkmark$ & $\checkmark$ & $\checkmark$ & $\checkmark$ & $\checkmark$ & \\
\hline & High & $\checkmark$ & $\checkmark$ & $\checkmark$ & $\checkmark$ & $\checkmark$ & $\checkmark$ & $\checkmark$ & $\checkmark$ & $\checkmark$ \\
\hline \multirow{2}{*}{$\begin{array}{l}\text { Department of } \\
\text { infectious diseases }\end{array}$} & Medium & $\checkmark$ & $\checkmark$ & $\checkmark$ & $\checkmark$ & $\checkmark$ & $\checkmark$ & $\checkmark$ & $\checkmark$ & \\
\hline & High & $\checkmark$ & $\checkmark$ & $\checkmark$ & $\checkmark$ & $\checkmark$ & $\checkmark$ & $\checkmark$ & $\checkmark$ & $\checkmark$ \\
\hline \multicolumn{11}{|c|}{ Recommendations as per personnel } \\
\hline \multirow{2}{*}{$\begin{array}{l}\text { Medical staff in the } \\
\text { isolation area }\end{array}$} & High & $\checkmark$ & $\checkmark$ & $\checkmark$ & $\checkmark$ & $\checkmark$ & $\checkmark$ & $\checkmark$ & $\checkmark$ & $\checkmark$ \\
\hline & Medium & $\checkmark$ & $\checkmark$ & $\checkmark$ & $\checkmark$ & $\checkmark$ & $\checkmark$ & $\checkmark$ & $\checkmark$ & \\
\hline $\begin{array}{l}\text { Staff in pre-examination } \\
\text { triage }\end{array}$ & Medium & $\checkmark$ & $\checkmark$ & $\checkmark$ & $\checkmark$ & $\checkmark$ & $\checkmark$ & $\checkmark$ & $\checkmark$ & \\
\hline $\begin{array}{l}\text { Medical staff in Out- } \\
\text { patient Department }\end{array}$ & Medium & $\checkmark$ & $\checkmark$ & $\checkmark$ & $\checkmark$ & $\checkmark$ & $\checkmark$ & $\checkmark$ & $\checkmark$ & \\
\hline \multirow{2}{*}{$\begin{array}{l}\text { Medical staff in the } \\
\text { observing ward }\end{array}$} & High & $\checkmark$ & $\checkmark$ & $\checkmark$ & $\checkmark$ & $\checkmark$ & $\checkmark$ & $\checkmark$ & $\checkmark$ & $\checkmark$ \\
\hline & Medium & $\checkmark$ & $\checkmark$ & $\checkmark$ & $\checkmark$ & $\checkmark$ & $\checkmark$ & $\checkmark$ & $\checkmark$ & \\
\hline Assisting staff & Medium & $\checkmark$ & $\checkmark$ & $\checkmark$ & $\checkmark$ & $\checkmark$ & $\checkmark$ & & & \\
\hline $\begin{array}{l}\text { Administrative and } \\
\text { supporting staff }\end{array}$ & Low & $\checkmark$ & $\checkmark$ & $\checkmark$ & $\checkmark$ & $\checkmark$ & $\checkmark$ & & & \\
\hline
\end{tabular}

closely monitor the patient's breathing and blood oxygen saturation. If oxygen therapy fails to reach the expected effect, the nurse should analyze the cause comprehensively and be vigilant to notify the doctor.

\subsubsection{Nursing of medication}

Mild patients generally use antiviral drugs, antibacterial drugs (when bacterial infection exists), and symptomatic treatment. The doctor's advice should be followed accurately and timely. The adverse reactions of oseltamivir mainly include nausea, vomiting, diarrhea, abdominal pain and bronchitis, cough, etc. The adverse reactions of interferon are mainly flu-like symptoms such as fever, fatigue, myalgia, and headache, followed by mild suppression of bone marrow. Attention should be paid to identify the change of clinical manifestations or adverse drug reactions.

\subsubsection{Nutritional support}

According to the patients' condition, provide highprotein, high-vitamin, carbohydrate-containing diets (e.g. eggs, fish, lean meat, milk, etc.) for enough nutrition to improve physical condition.

\subsubsection{Psychological nursing}

Take good care of the patient and respond to the patient's question timely. Positively encourage patients to reduce their anxiety and fear.

\subsection{Nursing of critically illed patients \\ 8.3.1 Condition monitoring}

Dynamically monitor patients' vital signs, waterelectrolytes balance, acid-base balance, and functions of various organs, monitor patients' infection indicators, and determine the occurrence of complications such as acute respiratory distress syndrome, septic shock, stress ulcers, and deep vein thrombosis.

\subsubsection{Sequential oxygen care}

The critically illed patients mainly use oxygen therapy such as HFNO, NIV and invasive mechanical ventilation. 
When using various oxygen treatments in a sequential manner, the airway and breathing circuit need to be kept open, and the effect of oxygen treatment needs to be monitored dynamically. At the same time, skincare products need to be used reasonably to avoid damage to the nose, face and lips by pressure. When using a high-flow nasal catheter to inhale oxygen, the oxygen flow and temperature and humidity should be adjusted appropriately. When using non-invasive mechanical ventilation, patient should receive relevant health education. Patients are instructed to inhale through the nose. The pressure is set from low to high and gradually reaches the target value. The human-machine coordination is maximized. The patient's consciousness and respiratory function are closely observed. Patients with artificial airway established should use a closed suction tube to reduce virus spread. Nurses should wear goggles or a face shield to avoid occupational exposure.

\subsubsection{Special treatment nursing}

If the patient develops moderate to severe ARDS, invasive mechanical ventilation combined with a prone position need to be adopted. Standard operating procedure for prone position needs to be followed. At the same time, be cautious to prevent pressure ulcers, falling bed, tube slippage, and eye damage by pressure and other complications. Patients treated with ECMO should be monitored for the performance of the oxygenator. If the oxygenator changes its color to darker, indicating the possibility of coagulation, the doctor should be notified to adjust the heparin dose as necessary. The oxygenator should be replaced if necessary. The coagulation function need to be monitored dynamically, including the whole set of coagulation and DIC (disseminated intravascular coagulation), and the time of activating partial thromboplastin, etc., the patient should be closely observed for signs of bleeding, such as bruising on the skin and mucous membranes, bleeding in the nasal cavity, oral cavity, bloody sputum, hematuria, blood in the stool, swelling of the abdomen, moving dullness, and the size of bilateral pupils. Make sure that the ECMO pipelines are tightly connected and firmly fixed to prevent air embolism and pipeline slippage.

\subsubsection{Infection prevention}

Perform oral care and skin care, assist the patient to use toilet, and take eyes on the indwelling tubes. Rules and regulations for aseptic operation and isolation should be strictly followed to prevent ventilator-related pneumonia, catheter-related sepsis, urinary catheter related urinary tract infections and other secondary infections.

\subsubsection{Nutrition support}

Dynamically assess the patients' nutritional risks and timely nutritional support can be given if needed. For the patients who can eat, the diet rich in protein and carbohydrates is recommended. Those patients who cannot eat but are compatible with enteral nutrition should be given enteral nutrition as soon as possible. For the patients incompatible with enteral nutrition, parenteral nutrition should be given timely to meet energy requirement.

\subsubsection{Psychological nursing}

Psychological and humanistic care should be performed in high priority especially for the awake patients. Psychological techniques like mindfulness - based stress reduction can be adopted to relieve the patients' anxiety and panic by building up their optimistic confidence in overcoming the disease.

\section{Limitations of this guideline}

Our guideline has three major limitations: Firstly, time is so limited that we cannot fully consider all clinical issues for this emergency disease. Secondly, many evidences came from data search is indirect. Thirdly, because some recommendations are based on the evidence from existing guidelines and experts' experience, there are situations where strong recommendations were produced on the base of low-quality evidence or very low-quality evidence, so high-quality evidence, when they appear, is likely to change current recommendations.

\section{Supplementary information}

Supplementary information accompanies this paper at https://doi.org/10. 1186/s40779-020-0233-6.

Additional file 1. A successful treatment case of the severe 2019-nCoV infected pneumonia patient.

Additional file 2. Experience and lessons in hospital rescue for 2019nCoV infections.

Abbreviations

2019-nCoV: 2019 novel coronavirus; ALT: Alanine aminotransferase; ARDS: Acute respiratory distress syndrome; AST: Aspartate aminotransferase; CCEBTCM: China Center for Evidence Based Traditional Chinese Medicine; CDC: Centers for Disease Control and Prevention; CK: Creatine kinase;

CPAM: China International Exchange and Promotive Association for Medical and Health Care; CPAP: Continuous positive airway pressure; CRP: C-reactive protein; CRRT: Continuous renal replacement therapies; DIC: Disseminated intravascular coagulation; ECLS: Extracorporeal life support;

ECMO: Extracorporeal membrane oxygenation; ESR: Erythrocyte sedimentation rate; GRADE: Grading of Recommendations Assessment, Development and Evaluation; HFNO: High flow nasal oxygen therapy; HFOV: High-frequency oscillatory ventilation; HRCT: High-resolution computed tomography; ICU: Intensive Care Unit; IL: Interleukin; MAP: Mean arterial pressure; MERS: Middle East respiratory syndrome; NGS: Next generation sequencing; NICE: National Institute for Health and Clinical Excellence; NIV: Non-invasive ventilation; PCT: Procalcitonin; PEEP: Positive end-expiratory pressure; PLT: Platelet; RCTs: Randomized controlled trials; SARS: Severe acute respiratory syndrome; SBT: Spontaneous breathing test; 
TB: tuberculosis; TNF: Tumor Necrosis Factor; WBC: White blood cells; WHO: World Health Organization

\section{Acknowledgements}

The authors thank all the staff of the Novel Coronavirus Management and Research Team in Zhongnan Hospital of Wuhan University, all the authors for their hard work for the included evidences in this guideline, and the staff of the Military Medical Research editorial office for their hard work. We also thank Hao Chen's help, the college of Acupuncture and Chinese Tuina, Nanjing University of Chinese Medicine.

\section{Authors' contributions}

WXH, WYY, HLQ, ZXT, ZY and LLK composed the Consultant/Advisor's panel. $C L, C Z S, C H, F Y P, H B, H F, L Y R, L K, M J, P Y B, P Z Y, P Z Y, S H M, W C J, W D F, X J, X Y$, $X H B, Y Y F, Y T S, Z X C, Z Y W, Z Y G$, and ZHM composed the Consensus experts' panel. DT, FC, HD, HQ, LBH, LLS, MLL, WYY, WH, ZMJ and ZH composed the Evidences synthesis panel. JYH, YXM (Canada) and RXQ were the methodologists. WY and HY were the secretaries. JYH, ZXT and the members of the evidences synthesis panel drafted the manuscript. All authors read and approved the final manuscript.

\section{Funding}

This work was supported (in part) by the Entrusted Project of National Center for Medical Service Administration, National Health and Family Planning Commission China (No. [2019]099), the First Level Funding of the Second Medical Leading Talent Project in Hubei Province, and the Special Project for Emergency of the Ministry of Science and Technology (2020YFC0841300).

\section{Availability of data and materials}

The data and materials used during the current review are all available in this review.

\section{Ethics approval and consent to participate} Not applicable.

\section{Consent for publication}

Written informed consent for publication of the clinical details and clinical images was obtained from all patients. A copy of the consent form is available for review by the Editor of this journal.

\section{Competing interests}

The funder had no role in study design, data collection and analysis, decision to publish, or preparation of the manuscript. The authors declare that there are no conflicts of interest in this study.

\section{Author details}

${ }^{1}$ Center for Evidence-Based and Translational Medicine, Zhongnan Hospital of Wuhan University, Wuhan 430071, China. ${ }^{2}$ Institute of Hospital Management, Wuhan University, Wuhan 430071, China. ${ }^{3}$ Department of Respiratory Medicine, Zhongnan Hospital of Wuhan University, Wuhan 430071, China. ${ }^{4}$ Department of Pharmacy, Zhongnan Hospital of Wuhan University, Wuhan 430071, China. ${ }^{5}$ Institute of Evidence-Based Medicine and Knowledge Translation, Henan University, Kaifeng 475000, China. ${ }^{6} \mathrm{China}$ Academy of Chinese Medical Sciences, Beijing 100700, China. ${ }^{7}$ China Center for Evidence Based Traditional Chinese Medicine (CCEBTCM), Beijing 100700, China. ${ }^{8}$ Department of Critical Care Medicine, Zhongnan Hospital of Wuhan University, Wuhan 430071, China. ${ }^{9}$ Department of Clinical Laboratory, Zhongnan Hospital of Wuhan University, Wuhan 430071, China. ${ }^{10}$ Department of Infectious Diseases, Zhongnan Hospital of Wuhan University, Wuhan 430071, China. ${ }^{11}$ Division of Medical Affairs, Zhongnan Hospital of Wuhan University, Wuhan 430071, China. ${ }^{12}$ Division of Nursing Affairs, Zhongnan Hospital of Wuhan University, Wuhan 430071, China. ${ }^{13}$ Office of Nosocomial Infection Control, Zhongnan Hospital of Wuhan University, Wuhan 430071, China. ${ }^{14}$ Emergency Center, Zhongnan Hospital of Wuhan University, Wuhan 430071, China. ${ }^{15}$ Department of Radiology, Zhongnan Hospital of Wuhan University, Wuhan 430071, China.

${ }^{16}$ Department of Health Research Methods, Evidence, and Impact, McMaster University, Hamilton, ON L8S 4L8, Canada. ${ }^{17}$ Department of Traditional Chinese Medicine, Zhongnan Hospital of Wuhan University, Wuhan 430071, China. ${ }^{18}$ Global Health Institute, Wuhan University, Wuhan 430072, China.
Received: 29 January 2020 Accepted: 30 January 2020

Published online: 06 February 2020

\section{References}

1. World Health Organization. WHO handbook for guideline development. 2nd ed; 2019. http://apps.who.int/medicinedocs/documents/s22083en/s22083en. pdf. Accessed 22 Jan 2020

2. Norris SL. WHO and rapid advice guidelines: history and future directions. 2013. https://g-i-n.net/conference/past-conferences/10th-conference/ monday/10-00-am-to-1-00-pm/norris-62.pdf/view. Accessed 22 Jan 2020.

3. Schünemann HJ, Zhang Y, Oxman AD, Expert Evidence in Guidelines Group. Distinguishing opinion from evidence in guidelines. BMJ. 2019;366:14606.

4. GRADE handbook, GRADE working group. 2013. https://gdt.gradepro.org/ app/handbook/handbook.html. Accessed 22 Jan 2020.

5. Guyatt $\mathrm{GH}$, Oxman AD, Vist GE, Kunz R, Falck-Ytter $Y$, Alonso-Coello $P$, et al. GRADE: an emerging consensus on rating quality of evidence and strength of recommendations. BMJ. 2008;336(7650):924-6.

6. Legault K, Schunemann H, Hillis C, et al. McMaster RARE-Bestpractices clinical practice guideline on diagnosis and management of the catastrophic antiphospholipid syndrome. J Thromb Haemost. 2018;16:1656-64.

7. Jin $Y H$, Cai L, Cheng ZS, Cheng H, Deng T, Fan YP, et al. A rapid advice guideline for the diagnosis and treatment of 2019 novel coronavirus (2019nCoV) infected pneumonia (Full version). Yixue Xinzhi. 2020;30(1):35-64. https://doi.org/10.12173/j.issn.1004-5511.2020.01.09 [Article in China].

8. Chan JFW, Yuan S, Kok KH, To KKT, Chu HC, Yang J, et al. A familial cluster of pneumonia associated with the 2019 novel coronavirus indicating person-to-person transmission: a study of a family cluster. Lancet. 2020. https://doi.org/10.1016/S0140-6736(20)30154-9.

9. Health Emergency Office of National Health Commission of the PRC. Update on the epidemic of novel coronavirus (2019-nCoV) infected pneumonia as at 24:00 on 26 January. http://www.nhc.gov.cn/xcs/yqfkdt/2 02001/3882fdcdbfdc4b4fa4e3a829b62d518e.shtml. Accessed 26 Jan 2020.

10. Zhou P, Yang XL, Wang XG, Hu B, Zhang L, Zhang W, et al. A pneumonia outbreak associated with a new coronavirus of probable bat origin. Nature. 2020. https://doi.org/10.1038/s41586-020-2012-7.

11. Perlman S. Another decade, another coronavirus. N Engl J Med. 2020. https://doi.org/10.1056/NEJMe2001126.

12. General Office of National Health Committee. Office of State Administration of Traditional Chinese Medicine. Notice on the issuance of a programme for the diagnosis and treatment of novel coronavirus (2019-nCoV) infected pneumonia (Trial Version 4). 2020. http://bgs.satcm.gov.cn/ zhengcewenjian/2020-01-28/12576.html. Accessed 29 Jan 2020.

13. Zhu N, Zhang D, Wang W, Li X, Yang B, Song J, et al. A novel coronavirus from patients with pneumonia in China, 2019. N Engl J Med. 2020. https:// doi.org/10.1056/NEJMoa2001017.

14. General Office of National Health Committee. Office of State Administration of Traditional Chinese Medicine. Notice on the issuance of a program for the diagnosis and treatment of novel coronavirus (2019-nCoV) infected pneumonia (Trial Version 3). 2020. http://www.nhc.gov.cn/xcs/zhengcwj/202 001/f492c9153ea9437bb587ce2ffcbee1fa.shtml. Accessed 24 Jan 2020.

15. Information Office of the State Council. Information office to hold press conference on joint preventing and controlling the epidemic of novel coronavirus (2019-nCoV) infected pneumonia. 2020. http://www.scio.gov.cn/ xwfbh/xwbfbh/wqfbh/42311/42478/index.htm. Accessed 26 Jan 2020.

16. Huang C, Wang Y, Li X, Ren L, Zhao J, Hu Y, et al. Clinical features of patients infected with 2019 novel coronavirus in Wuhan, China. Lancet. 2020. https://doi.org/10.1016/S0140-6736(20)30183-5.

17. Li L, Ren MJ, Zhang YY, Li WQ, Zhao HY, Liang LC, et al. Lung CT image of a confirmed case of the 2019 novel coronavirus (2019-nCoV) infected pneumonia (With differential diagnosis of the SARS). Yixue Xinzhi. 2020; 30(1):4-6 [Article in China].

18. Disease Control and Prevention Bureau of National Health and Health Commission. Program for prevention and control of novel coronavirus (2019-nCoV) infected pneumonia (Trial Version 2). 2020. http://www.nhc gov.cn/xcs/zhengcwj/202001/c67cfe29ecf1470e8c7fc47d3b751e88.shtml. Accessed 23 Jan 2020.

19. World Health Organization. Home care for patients with suspected novel coronavirus (nCoV) infection presenting with mild symptoms and management of contacts. 2020. https:/www.who.int/publications-detail/home-care-forpatients-with-suspected-novel-coronavirus-(ncov)-infection-presenting-with-mildsymptoms-and-management-of-contacts. Accessed 24 Jan 2020. 
20. Kim JY, Song JY, Yoon YK, Choi SH, Song YG, Kim SR, et al. Middle East respiratory syndrome infection control and prevention guideline for healthcare facilities. Infect Chemother. 2015;47(4):278-302.

21. Wang $Y$, Lin LK. An advice guideline recommended by central south hospital for the suspected patients of novel coronavirus (2019-nCoV) infected pneumonia and their close contactsas at home quarantine. 2020. https://mp.weixin.qq.com/s/xFO10WAFB9OUnM7VN92R2w. Accessed 25 Jan 2020.

22. World Health Organization. Infection prevention and control during health care when novel coronavirus (nCoV) infection is suspected. 2020. https:// www.who.int/publications-detail/infection-prevention-and-control-duringhealth-care-when-novel-coronavirus-(ncov)-infection-is-suspected-20200125. Accessed 26 Jan 2020

23. World Health Organization. WHO advice for international travel and trade in relation to the outbreak of pneumonia caused by a new coronavirus in China. 2020. https://www.who.int/ith/2020-0901_outbreak_of_Pneumonia_ caused_by_a_new_coronavirus_in_C/en/. Accessed 23 Jan 2020.

24. Centers for Disease Control and Prevention. CDC: travelers' health - novel coronavirus in China. 2020. https://wwwnc.cdc.gov/travel/notices/watch/ novel-coronavirus-china. Accessed 23 Jan 2020.

25. Wang W, Hu H, Song L, Gong X, Qu Y, Lu Z. Image of pulmonary and diagnosis of atypicalnovel coronavirus (2019-nCoV) infected pneumonia: case series of 14 patients. Yixue Xinzhi. 2020;30(1):7-9 [Article in China].

26. Chan KS, Lai ST, Chu CM, Tsui E, Tam CY, Wong MM, et al. Treatment of severe acute respiratory syndrome with lopinavir/ritonavir: a multicentre retrospective matched cohort study. Hong Kong Med J. 2003:9(6):399-406.

27. Chu CM, Cheng VC, Hung IF, Wong MM, Chan KH, Chan KS, et al. Role of lopinavir/ritonavir in the treatment of SARS: initial virological and clinical findings. Thorax. 2004;59(3):252-6.

28. Lai ST. Treatment of severe acute respiratory syndrome. Eur J Clin Microbiol Infect Dis. 2005;24(9):583-91.

29. Brigitte M, Arti B, Stephan A, Judith A, Bruno R, Christoph W, et al. MERSCOV disease associated ARDS -a case report. Crit Care Med. 2015;43(12):308.

30. Jiang H, Deng H, Wang Y, Liu Z, Sun WM. The possibility of using Lopinave/ Litonawe (LPV/r) as treatment for novel coronavirus 2019-nCov pneumonia: a quick systematic review based on earlier coronavirus clinical studies. Zhonghua Jizhen Yixue Zazhi. 2020;29(2):182-6 [Article in China].

31. Falzarano D, de Wit E, Rasmussen AL, Feldmann F, Okumura A, Scott DP, et al. Treatment with interferon-a2b and ribavirin improves outcome in MERS-CoV-infected rhesus macaques. Nat Med. 2013;19(10):1313-7.

32. Chan JF, Yao Y, Yeung ML, Deng W, Bao L, Jia L, et al. Treatment with lopinavir/ritonavir or interferon- $\beta 1 \mathrm{~b}$ improves outcome of MERS-CoV infection in a nonhuman primate model of common marmoset. J Infect Dis. 2015;212(12):1904-13.

33. Omrani AS, Saad MM, Baig K, Bahloul A, Abdul-Matin M, Alaidaroos AY, et al. Ribavirin and interferon alfa-2a for severe Middle East respiratory syndrome coronavirus infection: a retrospective cohort study. Lancet Infect Dis. 2014; 14(11):1090-5.

34. Khan PA, Nousheen BB, Maryam N, Sultana K. Middle east respiratory syndrome (MERS): a systematic review. Int J Pharm Sci Res. 2018:9(7):2616-25.

35. Zhao ZW, Zhang FC, Xu M, Huang K, Zhong WN, Cai WP, et al. Clinical analysis of 190 cases of outbreak with atypical pneumonia in Guangzhou in spring, 2003. Zhonghua Yixue Zazhi. 2003;83(9):713-8.

36. Meng QH, Dong PL, Guo YB, Zhang K, Liang LC, Hou W, et al. Use of glucocorticoid in treatment of severe acute respiratory syndrome cases. Zhonghua Yufang Yixue Zazhi. 2003;37(4):233-5 [Article in China].

37. Xiao JZ, Ma L, Gao J, Yang ZJ, Xing XY, Zhao HC, et al. Glucocorticoidinduced diabetes in severe acute respiratory syndrome: the impact of high dosage and duration of methylprednisolone therapy. Zhonghua Neike Zazhi. 2004;43(3):179-82 [Article in China].

38. ARDS Definition Task Force, Ranieri VM, Rubenfeld GD, Thompson BT, Ferguson ND, Caldwell E, et al. Acute respiratory distress syndrome: the Berlin Definition. JAMA. 2012;307(23):2526-33.

Ready to submit your research? Choose BMC and benefit from:

- fast, convenient online submission

- thorough peer review by experienced researchers in your field

- rapid publication on acceptance

- support for research data, including large and complex data types

- gold Open Access which fosters wider collaboration and increased citations

- maximum visibility for your research: over $100 \mathrm{M}$ website views per year

At BMC, research is always in progress.

Learn more biomedcentral.com/submissions 